\title{
Changes of perceived unevenness caused by in-track vibration countermeasures in slab track
}

\author{
R. Verachterta, ${ }^{a}$, H.E.M. Hunt ${ }^{\mathrm{b}}$, M.F.M. Hussein ${ }^{\mathrm{c}}$, G. Degrande ${ }^{\mathrm{a}}$ \\ ${ }^{a} K U$ Leuven, Department of Civil Engineering, Kasteelpark Arenberg 40, B-3001 Leuven, Belgium \\ ${ }^{b}$ University of Cambridge, Engineering Department, Trumpington Street, Cambridge CB2 1PZ, United Kingdom \\ ${ }^{c}$ University of Qatar, Department of Civil and Architectural Engineering, P.O. Box 2713, Doha, Qatar
}

\begin{abstract}
This paper investigates the relation between unevenness at different locations in a railway track and the unevenness perceived by a train, for the particular case of a slab track. The different types of unevenness considered are: slab and track bed unevenness, bent rail and bent slab, variation of rail pad stiffness, variation of slab bearing stiffness, and variation of rail and slab bending stiffness. The unevenness perceived by the wheels of a moving train is the result of all these types of unevenness. When vibration countermeasures, such as resilient elements (e.g. soft rail pads), are introduced in a track, the perceived unevenness is modified.

The slab track is modelled as a double beam supported on a rigid foundation. Analytical expressions are derived to relate the input and perceived unevenness. It is shown that in-track vibration countermeasures always introduce a change in perceived unevenness, which may turn out to be an increase or decrease and, consequently, result in a change of the performance of vibration countermeasures. This is illustrated for the particular case of a slab track on elastic supports on metro line M1 of ATM in Milan (Italy).

This paper shows that prediction of vibration insertion loss based on conventional models may lead to inaccuracies in absence of information about different sources of unevenness. After the installation of vibration countermeasures, it is advised to measure the perceived unevenness in order to interpret differences between predicted and measured insertion loss.
\end{abstract}

Keywords: slab track, perceived track unevenness, vibration countermeasures

\section{Introduction}

Railway induced vibrations can cause discomfort to people and disturb sensitive equipment. In order to reduce these vibrations, in-track vibration countermeasures, such as the introduction of resilient elements (e.g. soft rail pads or slab bearings), can be taken. Through a modification of the dynamic track characteristics, the interaction between the axle and the track and the force transfer function of the track are

\footnotetext{
*Corresponding author, tel: +321632 2231

Email addresses: ramses.verachtert@kuleuven.be (R. Verachtert), hemh1@cam.ac.uk (H.E.M. Hunt), mhussein@qu.edu.qa (M.F.M. Hussein), geert.degrande@kuleuven.be (G. Degrande) 
changed, which results in a reduction of high frequency vibrations. Vibrations are predicted before and after implementation of the countermeasure in order to assess its performance.

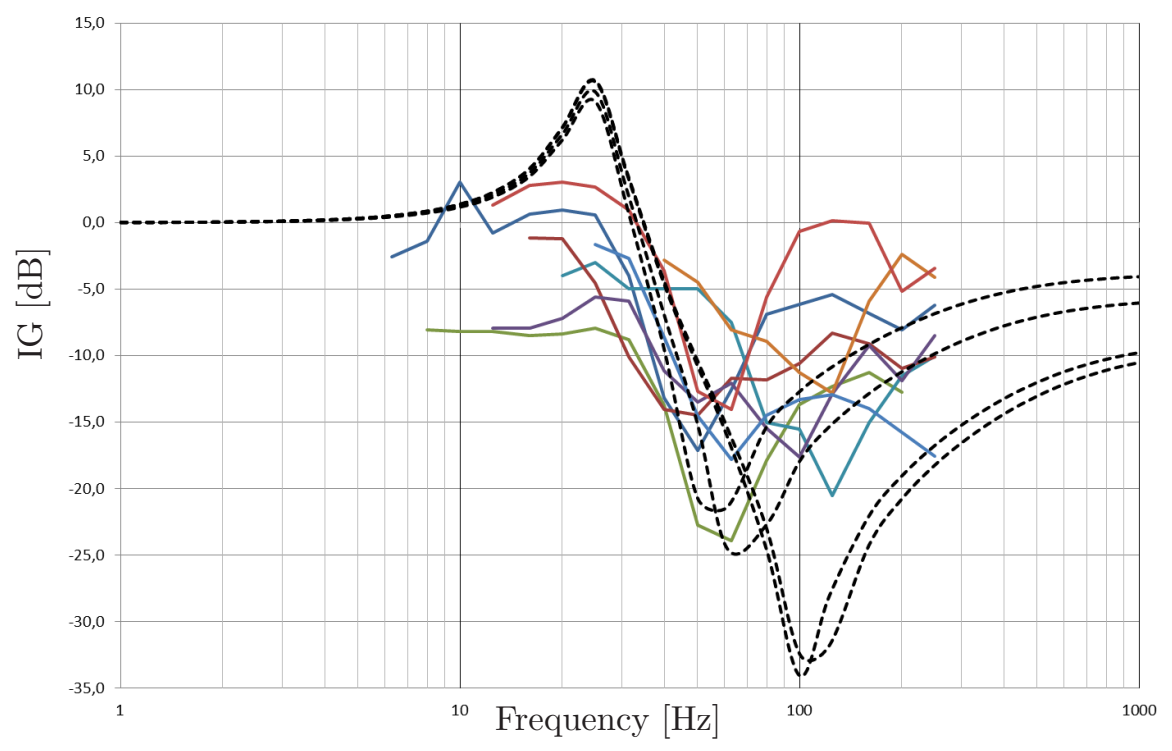

Figure 1: Predicted (black dashed lines) and measured (colored solid lines) insertion gain of base slab acceleration after the installation of resilient rail supports with a stiffness of $4 \mathrm{MN} / \mathrm{m}$ for eight slab or ballasted tracks around the world with an initial rail support stiffness equal to $20 \mathrm{MN} / \mathrm{m}$ (dark blue, red and pink solid lines), $30 \mathrm{MN} / \mathrm{m}$ (green solid line), $80 \mathrm{MN} / \mathrm{m}$ (light blue solid line) and $100 \mathrm{MN} / \mathrm{m}$ (purple, orange and gray solid lines) [1].

Correct prediction of vibration mitigation performance is important for deciding which vibration countermeasures need to be chosen, in order to minimize costs. It is, however, often found that the predicted performance of vibration countermeasures is not in accordance with the measured performance. When applied to different sites with similar track characteristics, the same countermeasure may lead to different reduction in vibrations. Figure 1 shows the measured insertion gain of base slab acceleration after the installation of resilient rail supports with a stiffness of $4 \mathrm{MN} / \mathrm{m}$ for eight slab or ballasted tracks around the world with an initial rail support stiffness equal to $20 \mathrm{MN} / \mathrm{m}, 30 \mathrm{MN} / \mathrm{m}, 80 \mathrm{MN} / \mathrm{m}$ and $100 \mathrm{MN} / \mathrm{m}[1]$. For each track, the performance of the vibration countermeasure is predicted using a beam on elastic foundation model. The same rail type was used in combination with the initial rail pad stiffness, resulting in four model predictions [1], that all show a peak around $25 \mathrm{~Hz}$, which is the axle-track resonance frequency after installation of the resilient rail support. The insertion gain is positive for frequencies up to $35 \mathrm{~Hz}$, corresponding to an increase in base slab acceleration. For higher frequencies, vibration reduction is predicted, which is largest at the axle-track resonance frequency before the installation of the resilient rail support. Comparison between the measured and predicted vibration insertion gain reveals that, in most cases, the performance of the vibration countermeasure is not accurately predicted. Particularly at low frequencies, reductions in vibration levels are found that cannot be explained by a change of the dynamic track characteristics.

One of the main input parameters in vibration prediction modelsis is the track unevenness spectrum, 
together with track, tunnel, soil and building parameters. When the wheels of the train move over an uneven track, dynamic loads are applied to the rails [2]. Different models exist to calculate excitation forces and vibration levels from measured unevenness spectra $[3,4]$. An overview of methods to measure rail unevenness is given by Verheijen [5].

Besides geometrical unevenness, parametric unevenness related to the variation of track stiffness versus distance is an important vibration excitation source. This can be further differentiated into the stiffness variation related to sleeper periodicity and broad band stiffness variation related to spatially varying track characteristics [6]. Nélain et al. [7] and Nélain and Vincent [8] studied the parametric unevenness due to sleeper periodicity, random sleeper stiffness and variation of foundation stiffness (ballast and subsoil) along the track. They found that softer rail pads result in vibration reduction at low frequencies, which is not observed for vibrations due to rail irregularities. For normally loaded trains, sleeper periodicity is the dominant vibration source at the sleeper passing frequency. In the low frequency range, however, the excitation related to random variation of the subsoil stiffness is not predominant over geometrical unevenness.

Hunt [9] showed that, when (dynamic) track parameters are modified, the perceived unevenness is likely to change as well. This perceived unevenness can be due to both geometrical unevenness and parametric unevenness. He demonstrated how the unevenness is modified for the case of a track represented by an Euler-Bernoulli beam on a Winkler foundation [10,11]. Auersch [12] also studied perceived unevenness in ballast and slab track, due to track irregularities and variation of soil stiffness, using a beam on elastic foundation. The influence of sleeper stiffness, slab thickness, and soil stiffness on perceived unevenness were investigated and found to be in accordance with the findings of Hunt. The performance of a track without and with under-sleeper pads was also compared, the latter resulting in vibration reduction around $16 \mathrm{~Hz}$ that could only be explained by a reduction in perceived unevenness.

The present paper extends this research for eight geometrical and parametric unevenness sources in the case of a floating slab track (FST), as frequently used in railway tunnels. Although a continuously supported track model is used, results are also valid for a discretely supported track for frequencies below half of the sleeper passing frequency [13]. It is investigated how, depending on the type and the wavelength of the unevenness, the insertion of resilient rail supports can have beneficial or negative effects on the unevenness perceived by the train and, therefore, on the vibration levels. For the particular case of metro line M1 of Azienda Trasporti Milanesi (ATM) in Milan (Italy), it is shown that a realistic change in unevenness, due to the replacement of the original stiff rail pads by the flexible Pandrol Vanguard rail support system [14], can explain the observed reduction of vibration velocity levels at low frequencies, which can not be explained by a modification of the dynamic track characteristics only.

The outline of the paper is as follows. Section 2 presents the analytical model of a floating slab track; the rail deflection under a static axle load is calculated. In section 3 , the transfer functions which determine the relation between each unevenness source and the perceived unevenness are introduced. In section 4, the 
transfer functions for the case of a slab track on elastic foundation on metro line M1 of ATM in Milan (Italy) are discussed, as well as the insertion gain functions, which describe the change in perceived unevenness after the stiff rail pads were replaced by a resilient rail support system. The concept of unevenness smoothing is introduced. Measured changes in free field vibration levels after the insertion of resilient rail supports are shown. An analytical train model is coupled to the track model in order to calculate the dynamic effects due to the change in rail support. The calculated insertion gain of the transmitted forces is compared to the measured insertion gain. Realistic unevenness values are deduced for different unevenness sources in section 5 for the old and the new track and the importance of a change in perceived unevenness is discussed. Conclusions are formulated in section 6.

\section{Dynamic model of the FST}

In order to investigate the influence of different unevenness types, an analytical track model with a double beam on a rigid foundation is used, which is an extension of a beam on Winkler foundation model $[15,16]$. Shamalta and Metrikine [17] showed that results obtained with this simplified model compare very well with results obtained with a more detailed track model. This model was also used by Forrest and Hunt [18, 19] and Hussein and Hunt [20]. Kuo et al. [21] used a similar analytical approach to investigate the vibration characteristics of a FST, including the sleeper and slab bearing spacing.

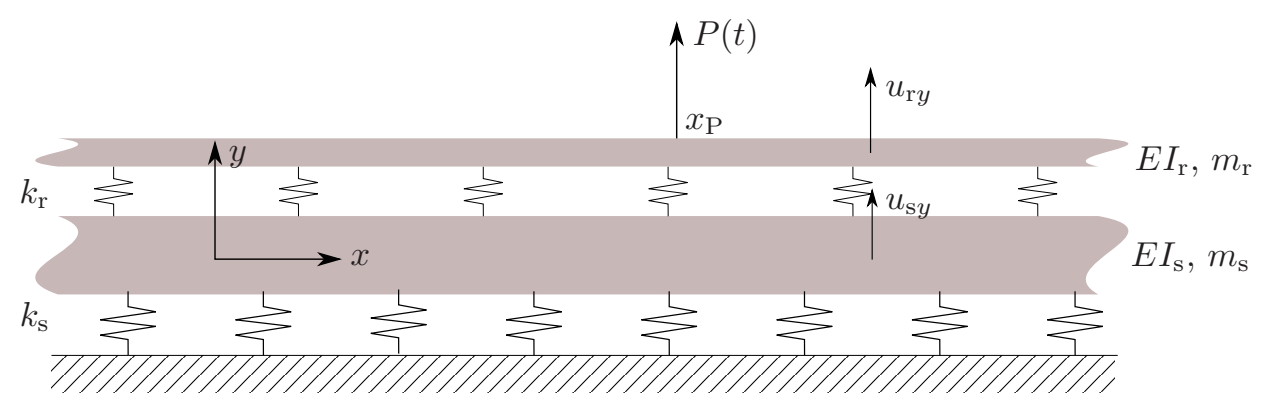

Figure 2: Model of a FST.

Both rails in the model are combined to a single beam with bending stiffness $E I_{\mathrm{r}}$ and mass per unit length $m_{\mathrm{r}}$ (figure 2). The rail pads are represented by uniform springs with stiffness $k_{\mathrm{r}}$. Thompson [22] showed that, for frequencies up to $500 \mathrm{~Hz}$, shear deformation in the rails can be neglected, so that Euler-Bernoulli beam theory can be used in the low frequency range of interest in his paper. Similarly, Shamalta and Metrikine [17] demonstrated that Euler-Bernoulli beam theory and Kirchhoff plate theory can adequately be used to model a slab track in the range of frequencies and train speeds that are of practical relevance here. The concrete slab is therefore also modelled as an Euler-Bernoulli beam with bending stiffness $E I_{\mathrm{s}}$ and mass per unit length $m_{\mathrm{s}}$. The slab bearings are represented by uniform springs with stiffness $k_{\mathrm{s}}$. A rigid foundation is used, as weak coupling between the track and the tunnel is assumed [23]. 
The system of equilibrium equations for a slab track subjected to a single moving axle load $P(t)$ with speed $v$ and initial position $x_{\mathrm{P}}$ can be written as:

$$
\begin{aligned}
\frac{\partial^{2}}{\partial x^{2}}\left(E I_{\mathrm{r}} \frac{\partial^{2} u_{\mathrm{r} y}}{\partial x^{2}}\right)+m_{\mathrm{r}} \frac{\partial^{2} u_{\mathrm{r} y}}{\partial t^{2}}+k_{\mathrm{r}}\left(u_{\mathrm{r} y}-u_{\mathrm{s} y}\right) & =P(t) \delta\left(x-x_{\mathrm{P}}-v t\right), \\
\frac{\partial^{2}}{\partial x^{2}}\left(E I_{\mathrm{s}} \frac{\partial^{2} u_{\mathrm{s} y}}{\partial x^{2}}\right)+m_{\mathrm{s}} \frac{\partial^{2} u_{\mathrm{s} y}}{\partial t^{2}}+k_{\mathrm{s}} u_{\mathrm{s} y}-k_{\mathrm{r}}\left(u_{\mathrm{r} y}-u_{\mathrm{s} y}\right) & =0,
\end{aligned}
$$

where the vertical displacement of the rail and slab at position $x$ and time $t$ are denoted as $u_{\mathrm{r} y}(x, t)$ and $u_{\mathrm{s} y}(x, t)$, respectively, and $\delta(x)$ is the Dirac delta function. The axle load $P(t)$ is equal to the sum of the static axle load $P_{\mathrm{s}}$, determined by the weight carried by the axle, and the dynamic axle load $P_{\mathrm{d}}(t)$, which depends on the (perceived) track unevenness.

Sheng et al. [2] showed that the track displacement and thus the perceived unevenness caused by parametric unevenness, resulting from a difference in rail deflection due to spatially varying track characteristics, is primarily influenced by the static axle load $P_{\mathrm{s}}$, which is larger than the dynamic axle load $P_{\mathrm{d}}(t)$. The perceived unevenness due to parametric unevenness will therefore not increase due to the dynamic axle loads it generates. So, dynamic vehicle-track interaction does not need to be taken into account for the calculation of perceived unevenness. Sheng et al. [24] also showed that, for train speeds well below the critical speed of the track-tunnel-soil system and for a large range of frequencies, the train speed has little effect on the dynamic axle loads and the displacement of the wheel-rail contact point. The track deflection can therefore be determined in good approximation by considering a non-moving load. Both approximations allow to neglect the time and speed dependence of the load, as well as the inertia terms in the equilibrium equations (1) and (2) for the calculation of the perceived unevenness. When the bending stiffness of the rails and the slab are constant, both equations simplify to:

$$
\begin{aligned}
E I_{\mathrm{r}} \frac{\mathrm{d}^{4} u_{\mathrm{r} y}}{\mathrm{~d} x^{4}}+k_{\mathrm{r}}\left(u_{\mathrm{r} y}-u_{\mathrm{s} y}\right) & =P_{\mathrm{s}} \delta\left(x-x_{\mathrm{P}}\right), \\
E I_{\mathrm{s}} \frac{\mathrm{d}^{4} u_{\mathrm{s} y}}{\mathrm{~d} x^{4}}+k_{\mathrm{s}} u_{\mathrm{s} y}-k_{\mathrm{r}}\left(u_{\mathrm{r} y}-u_{\mathrm{s} y}\right) & =0 .
\end{aligned}
$$

These equations are divided by $E I_{\mathrm{r}}$ and $E I_{\mathrm{s}}$, respectively, to obtain:

$$
\left\{\begin{array}{c}
\frac{\mathrm{d}^{4} u_{\mathrm{r} y}}{\mathrm{~d} x^{4}} \\
\frac{\mathrm{d}^{4} u_{\mathrm{s} y}}{\mathrm{~d} x^{4}}
\end{array}\right\}+\left[\begin{array}{cc}
+\alpha_{\mathrm{rr}} & -\alpha_{\mathrm{rr}} \\
-\alpha_{\mathrm{rs}} & \alpha_{\mathrm{ss}}+\alpha_{\mathrm{rs}}
\end{array}\right]\left\{\begin{array}{c}
u_{\mathrm{r} y} \\
u_{\mathrm{s} y}
\end{array}\right\}=\left\{\begin{array}{c}
\frac{P_{\mathrm{s}}}{E I_{\mathrm{r}}} \delta\left(x-x_{\mathrm{P}}\right) \\
0
\end{array}\right\}
$$

where $\alpha_{\mathrm{rr}}=k_{\mathrm{r}} /\left(E I_{\mathrm{r}}\right), \alpha_{\mathrm{rs}}=k_{\mathrm{r}} /\left(E I_{\mathrm{S}}\right)$ and $\alpha_{\mathrm{ss}}=k_{\mathrm{s}} /\left(E I_{\mathrm{s}}\right)$.

Equation (5) is subsequently transformed to the wavenumber domain using the following definition of 
the forward Fourier transform:

$$
\tilde{u}_{\mathrm{r} y}\left(k_{x}\right)=\int_{-\infty}^{\infty} u_{\mathrm{r} y}(x) \mathrm{e}^{+\mathrm{j} k_{x} x} \mathrm{~d} x .
$$

The inverse Fourier transform is defined as:

$$
u_{\mathrm{r} y}(x)=\frac{1}{2 \pi} \int_{-\infty}^{\infty} \tilde{u}_{\mathrm{r} y}\left(k_{x}\right) \mathrm{e}^{-\mathrm{j} k_{x} x} \mathrm{~d} k_{x}
$$

This results in:

$$
\left[\begin{array}{cc}
k_{x}^{4}+\alpha_{\mathrm{rr}} & -\alpha_{\mathrm{rr}} \\
-\alpha_{\mathrm{rs}} & k_{x}^{4}+\alpha_{\mathrm{ss}}+\alpha_{\mathrm{rs}}
\end{array}\right]\left\{\begin{array}{c}
\tilde{u}_{\mathrm{r} y}\left(k_{x}\right) \\
\tilde{u}_{\mathrm{s} y}\left(k_{x}\right)
\end{array}\right\}=\left\{\begin{array}{c}
\frac{P_{\mathrm{s}}}{E I_{\mathrm{r}}} \mathrm{e}^{+\mathrm{j} k_{x} x_{\mathrm{P}}} \\
0
\end{array}\right\}
$$

This linear system of equations is solved for $\tilde{u}_{\mathrm{r} y}\left(k_{x}\right)$ and $\tilde{u}_{\mathrm{s} y}\left(k_{x}\right)$ :

$$
\begin{aligned}
& \tilde{u}_{\mathrm{r} y}\left(k_{x}\right)=\frac{P_{\mathrm{s}}}{E I_{\mathrm{r}}} \frac{k_{x}^{4}+\alpha_{\mathrm{rs}}+\alpha_{\mathrm{ss}}}{k_{x}^{8}+k_{x}^{4}\left(\alpha_{\mathrm{rs}}+\alpha_{\mathrm{rr}}+\alpha_{\mathrm{ss}}\right)+\alpha_{\mathrm{rr}} \alpha_{\mathrm{ss}}} \mathrm{e}^{+\mathrm{j} k_{x} x_{\mathrm{P}}}, \\
& \tilde{u}_{\mathrm{s} y}\left(k_{x}\right)=\frac{P_{\mathrm{s}}}{E I_{\mathrm{r}}} \frac{\alpha_{\mathrm{rs}}}{k_{x}^{8}+k_{x}^{4}\left(\alpha_{\mathrm{rs}}+\alpha_{\mathrm{rr}}+\alpha_{\mathrm{ss}}\right)+\alpha_{\mathrm{rr}} \alpha_{\mathrm{ss}}} \mathrm{e}^{+\mathrm{j} k_{x} x_{\mathrm{P}}} .
\end{aligned}
$$

The denominator of these fractions will be denoted as $D\left(k_{x}\right)$. The vertical rail displacement $u_{\mathrm{r} y}(x)$ due to the load $P_{\mathrm{s}}$ can now be calculated by performing the inverse Fourier transformation of $\tilde{u}_{\mathrm{r} y}\left(k_{x}\right)$ :

$$
u_{\mathrm{r} y}(x)=\frac{1}{2 \pi} \frac{P_{\mathrm{s}}}{E I_{\mathrm{r}}} \int_{-\infty}^{\infty} \frac{k_{x}^{4}+\alpha_{\mathrm{rs}}+\alpha_{\mathrm{SS}}}{D\left(k_{x}\right)} \mathrm{e}^{-\mathrm{j} k_{x}\left(x-x_{\mathrm{P}}\right)} \mathrm{d} k_{x} .
$$

Evaluation of the rail displacement $u_{\mathrm{r} y}\left(x_{\mathrm{P}}\right)$ at the position $x_{\mathrm{P}}$ of the load $P_{\mathrm{s}}$ results in:

$$
u_{\mathrm{r} y}\left(x_{\mathrm{P}}\right)=\frac{1}{2 \pi} \frac{P_{\mathrm{s}}}{E I_{\mathrm{r}}} \int_{-\infty}^{\infty} \frac{k_{x}^{4}+\alpha_{\mathrm{rs}}+\alpha_{\mathrm{ss}}}{D\left(k_{x}\right)} \mathrm{d} k_{x} .
$$

This inverse wavenumber integral can be solved analytically, using contour integration [25, 13]. It is not possible, however, to determine in a closed form which poles of the integrand have a positive real part. Therefore, a closed form solution of equation (12) does not exist.

\section{Sources of track unevenness and their effect on perceived unevenness}

In this paper, eight sources of (random) track unevenness for a FST are considered (table 1). Each of these unevenness sources modifies the equilibrium equations (3) and (4) in a different way. They are divided into four geometrical and four parametric unevenness sources. The four geometrical sources are: slab and track bed unevenness, due to unevenness at the surface of the slab and track bed, and bent rail and bent slab, representing the initial deflection of the neutral line of the rail and slab. The four parametric unevenness sources are: variation of rail and slab support stiffness and variation of rail and slab bending stiffness. It is 
recognized that variation of rail bending stiffness is expected to be very small; it is only included here for completeness and complementarity with the more likely case of variation of slab bending stiffness.

Table 1: Sources of track unevenness.

\begin{tabular}{|ll|lll|}
\hline Case & Icon & Case & Icon \\
\hline 1a Slab unevenness & & & 1b Track bed unevenness \\
\hline & & & & \\
\hline 2a Bent rail & - & 2b Bent slab & \\
\hline 3a Variation of rail support stiffness & - & 3b Variation of slab bearing stiffness & \\
\hline & & & & \\
\hline
\end{tabular}

Rail corrugation or surface irregularity of the rail head is not included in table 1, as this type of unevenness is not considered to be important for generation of low frequency vibration. Changing the track properties will not result in a modification of the nature of the unevenness, but may have an effect on rail corrugation. The influence of rail pad stiffness on rail corrugation, for example, has been studied by Egana et al. [26]. Wheel out of roundness may also cause vibrations, but is a property of the wheel which can be controlled through a suitable maintenance programme.

\subsection{Slab unevenness}

The first type of unevenness is slab unevenness. When the slab surface is uneven, this may generate unevenness on top of the rails. The profile of the top of the slab is described by $u_{\mathrm{ty}}(x)$ (figure 3$)$. The system of equilibrium equations becomes:

$$
\begin{aligned}
\frac{\mathrm{d}^{4} u_{\mathrm{r} y}}{\mathrm{~d} x^{4}}+\alpha_{\mathrm{rr}}\left(u_{\mathrm{r} y}-u_{\mathrm{s} y}-u_{\mathrm{t} y}\right) & =\frac{P_{\mathrm{s}}}{E I_{\mathrm{r}}} \delta\left(x-x_{\mathrm{P}}\right), \\
\frac{\mathrm{d}^{4} u_{\mathrm{s} y}}{\mathrm{~d} x^{4}}+\alpha_{\mathrm{ss}} u_{\mathrm{s} y}-\alpha_{\mathrm{rs}}\left(u_{\mathrm{r} y}-u_{\mathrm{s} y}-u_{\mathrm{t} y}\right) & =0 .
\end{aligned}
$$

The same procedure as in section 2 is followed to obtain the equilibrium equations in the wavenumber 


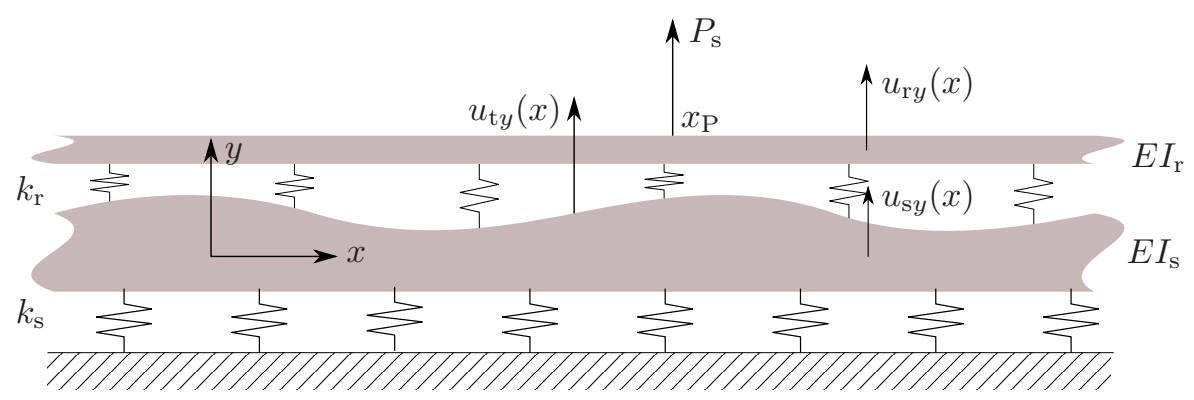

Figure 3: FST with slab unevenness $u_{\mathrm{t} y}(x)$.

domain:

$$
\left[\begin{array}{cc}
k_{x}^{4}+\alpha_{\mathrm{rr}} & -\alpha_{\mathrm{rr}} \\
-\alpha_{\mathrm{rs}} & k_{x}^{4}+\alpha_{\mathrm{ss}}+\alpha_{\mathrm{rs}}
\end{array}\right]\left\{\begin{array}{c}
\tilde{u}_{\mathrm{r} y}\left(k_{x}\right) \\
\tilde{u}_{\mathrm{s} y}\left(k_{x}\right)
\end{array}\right\}=\left\{\begin{array}{c}
\frac{P_{\mathrm{s}}}{E I_{\mathrm{r}}} \mathrm{e}^{+\mathrm{j} k_{x} x_{\mathrm{P}}}+\alpha_{\mathrm{rr}} \tilde{u}_{\mathrm{t} y}\left(k_{x}\right) \\
-\alpha_{\mathrm{rs}} \tilde{u}_{\mathrm{t} y}\left(k_{x}\right)
\end{array}\right\} .
$$

These equations are solved for $\tilde{u}_{\mathrm{r} y}\left(k_{x}\right)$, resulting in:

$$
\tilde{u}_{\mathrm{r} y}\left(k_{x}\right)=\frac{P_{\mathrm{s}}}{E I_{\mathrm{r}}} \frac{k_{x}^{4}+\alpha_{\mathrm{rs}}+\alpha_{\mathrm{ss}}}{D\left(k_{x}\right)} \mathrm{e}^{+\mathrm{j} k_{x} x_{\mathrm{P}}}+\frac{\alpha_{\mathrm{rr}}\left(k_{x}^{4}+\alpha_{\mathrm{ss}}\right)}{D\left(k_{x}\right)} \tilde{u}_{\mathrm{t} y}\left(k_{x}\right) .
$$

The deflection $u_{\mathrm{r} y}\left(x_{\mathrm{P}}\right)$ under the load $P_{\mathrm{s}}$ at position $x_{\mathrm{P}}$ is is equal to:

$$
u_{\mathrm{r} y}\left(x_{\mathrm{P}}\right)=\frac{1}{2 \pi} \frac{P_{\mathrm{s}}}{E I_{\mathrm{r}}} \int_{-\infty}^{\infty} \frac{k_{x}^{4}+\alpha_{\mathrm{rs}}+\alpha_{\mathrm{ss}}}{D\left(k_{x}\right)} \mathrm{d} k_{x}+\frac{1}{2 \pi} \int_{-\infty}^{\infty} \frac{\alpha_{\mathrm{rr}}\left(k_{x}^{4}+\alpha_{\mathrm{ss}}\right)}{D\left(k_{x}\right)} \tilde{u}_{\mathrm{t} y}\left(k_{x}\right) \mathrm{e}^{-\mathrm{j} k_{x} x_{\mathrm{P}}} \mathrm{d} k_{x} .
$$

The first integral on the right hand side of equation (17) is the same as equation (12) and represents the deflection when no unevenness is present; it will be denoted as $u_{\mathrm{r} y}^{0}\left(x_{\mathrm{P}}\right)$. The second term represents the variation in deflection or perceived unevenness $u_{1 \mathrm{a}}\left(x_{\mathrm{P}}\right)$ under the load as it moves on the uneven track:

$$
u_{1 \mathrm{a}}\left(x_{\mathrm{P}}\right)=\frac{1}{2 \pi} \int_{-\infty}^{\infty} \frac{\alpha_{\mathrm{rr}}\left(k_{x}^{4}+\alpha_{\mathrm{ss}}\right)}{D\left(k_{x}\right)} \tilde{u}_{\mathrm{ty}}\left(k_{x}\right) \mathrm{e}^{-\mathrm{j} k_{x} x_{\mathrm{P}}} \mathrm{d} k_{x} .
$$

The Fourier transform of the load position $x_{\mathrm{P}}$ to the wavenumber $k_{x_{\mathrm{P}}}$ results in:

$$
\begin{aligned}
\tilde{u}_{1 \mathrm{a}}\left(k_{x_{\mathrm{P}}}\right) & =\int_{-\infty}^{\infty}\left\{\frac{1}{2 \pi} \int_{-\infty}^{\infty} \frac{\alpha_{\mathrm{rr}}\left(k_{x}^{4}+\alpha_{\mathrm{ss}}\right)}{D\left(k_{x}\right)} \tilde{u}_{\mathrm{t} y}\left(k_{x}\right) \mathrm{e}^{-\mathrm{j} k_{x} x_{\mathrm{P}}} \mathrm{d} k_{x}\right\} \mathrm{e}^{+\mathrm{j} k_{x_{\mathrm{P}}} x_{\mathrm{P}}} \mathrm{d} x_{\mathrm{P}} \\
& =\frac{1}{2 \pi} \int_{-\infty}^{\infty} \frac{\alpha_{\mathrm{rr}}\left(k_{x}^{4}+\alpha_{\mathrm{ss}}\right)}{D\left(k_{x}\right)} \tilde{u}_{\mathrm{t} y}\left(k_{x}\right)\left\{\int_{-\infty}^{\infty} \mathrm{e}^{-\mathrm{j}\left(k_{x}-k_{x_{\mathrm{P}}}\right) x_{\mathrm{P}}} \mathrm{d} x_{\mathrm{P}}\right\} \mathrm{d} k_{x} .
\end{aligned}
$$

The term between brackets is equal to $2 \pi \delta\left(k_{x}-k_{x_{\mathrm{P}}}\right)$, so that:

$$
\tilde{u}_{1 \mathrm{a}}\left(k_{x_{\mathrm{P}}}\right)=\frac{\alpha_{\mathrm{rr}}\left(k_{x_{\mathrm{P}}}^{4}+\alpha_{\mathrm{ss}}\right)}{D\left(k_{x_{\mathrm{P}}}\right)} \tilde{u}_{\mathrm{ty}}\left(k_{x_{\mathrm{P}}}\right) .
$$

The transfer function $\tilde{T}_{1 \mathrm{a}}\left(k_{x_{\mathrm{P}}}\right)$ relates the slab unevenness $\tilde{u}_{\mathrm{ty}}\left(k_{x_{\mathrm{P}}}\right)$ to the perceived unevenness $\tilde{u}_{1 \mathrm{a}}\left(k_{x_{\mathrm{P}}}\right)$ 
and is given by:

$$
\tilde{T}_{1 \mathrm{a}}\left(k_{x_{\mathrm{P}}}\right)=\frac{\alpha_{\mathrm{rr}}\left(k_{x_{\mathrm{P}}}^{4}+\alpha_{\mathrm{ss}}\right)}{D\left(k_{x_{\mathrm{P}}}\right)} .
$$

\subsection{Track bed unevenness}

Apart from the slab surface, also the track invert can be uneven. The track bed is described by its profile $u_{\mathrm{f} y}(x)$ (figure 4$)$. The system of equilibrium equations becomes:

$$
\begin{aligned}
\frac{\mathrm{d}^{4} u_{\mathrm{r} y}}{\mathrm{~d} x^{4}}+\alpha_{\mathrm{rr}}\left(u_{\mathrm{r} y}-u_{\mathrm{s} y}\right) & =\frac{P_{\mathrm{s}}}{E I_{\mathrm{r}}} \delta\left(x-x_{\mathrm{P}}\right), \\
\frac{\mathrm{d}^{4} u_{\mathrm{s} y}}{\mathrm{~d} x^{4}}+\alpha_{\mathrm{ss}}\left(u_{\mathrm{s} y}-u_{\mathrm{f} y}\right)-\alpha_{\mathrm{rs}}\left(u_{\mathrm{r} y}-u_{\mathrm{s} y}\right) & =0 .
\end{aligned}
$$

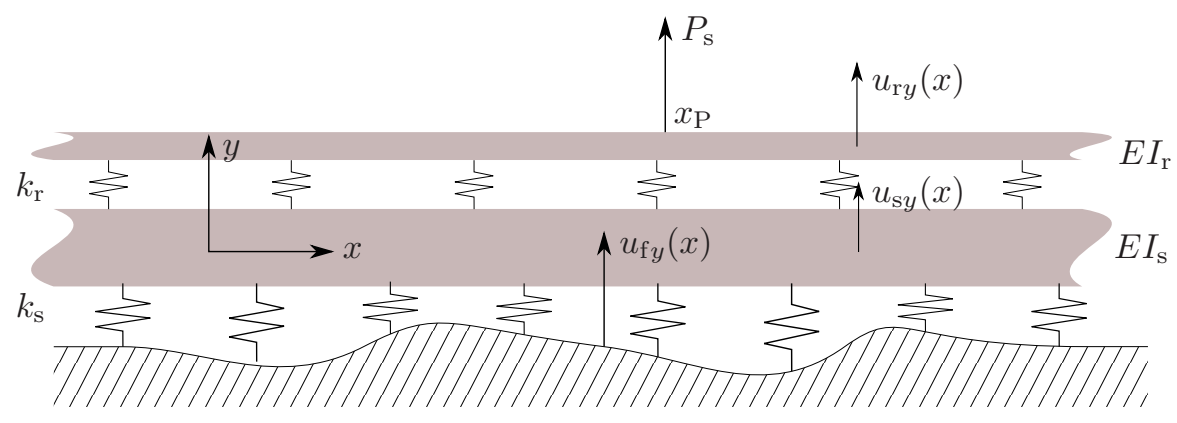

Figure 4: FST with track bed unevenness $u_{\mathrm{f} y}(x)$.

The same procedure as before is followed to obtain the equilibrium equations in the wavenumber domain:

$$
\left[\begin{array}{cc}
k_{x}^{4}+\alpha_{\mathrm{rr}} & -\alpha_{\mathrm{rr}} \\
-\alpha_{\mathrm{rs}} & k_{x}^{4}+\alpha_{\mathrm{ss}}+\alpha_{\mathrm{rs}}
\end{array}\right]\left\{\begin{array}{c}
\tilde{u}_{\mathrm{r} y}\left(k_{x}\right) \\
\tilde{u}_{\mathrm{s} y}\left(k_{x}\right)
\end{array}\right\}=\left\{\begin{array}{c}
\frac{P_{\mathrm{s}}}{E I_{\mathrm{r}}} \mathrm{e}^{+\mathrm{j} k_{x} x_{\mathrm{P}}} \\
\alpha_{\mathrm{ss}} \tilde{u}_{\mathrm{f} y}\left(k_{x}\right)
\end{array}\right\} .
$$

The transfer function $\tilde{T}_{1 \mathrm{~b}}\left(k_{x_{\mathrm{P}}}\right)$ relates the track bed unevenness $\tilde{u}_{\mathrm{f} y}\left(k_{x_{\mathrm{P}}}\right)$ to the perceived unevenness $\tilde{u}_{1 \mathrm{~b}}\left(k_{x_{\mathrm{P}}}\right)$ :

$$
\tilde{T}_{1 \mathrm{~b}}\left(k_{x_{\mathrm{P}}}\right)=\frac{\alpha_{\mathrm{rr}} \alpha_{\mathrm{ss}}}{D\left(k_{x_{\mathrm{P}}}\right)}
$$

\subsection{Bent rail}

If the rails are not perfectly straight, the initial position of their neutral line can be described by $u_{\text {riy }}(x)$ (figure 5). The bending moment in the rail is equal to $E I_{\mathrm{r}} \mathrm{d}^{2}\left(u_{\mathrm{r} y}-u_{\mathrm{ri} y}\right) / \mathrm{d} x^{2}$, where $u_{\mathrm{r} y}-u_{\mathrm{ri} y}$ is the deviation 
from the original deflected shape. The system of equilibrium equations becomes:

$$
\begin{aligned}
& \frac{\mathrm{d}^{4}\left(u_{\mathrm{r} y}-u_{\mathrm{r} i y}\right)}{\mathrm{d} x^{4}}+\alpha_{\mathrm{rr}}\left(u_{\mathrm{r} y}-u_{\mathrm{s} y}\right)=\frac{P_{\mathrm{s}}}{E I_{\mathrm{r}}} \delta\left(x-x_{\mathrm{P}}\right), \\
& \frac{\mathrm{d}^{4} u_{\mathrm{s} y}}{\mathrm{~d} x^{4}}+\alpha_{\mathrm{ss}} u_{\mathrm{s} y}-\alpha_{\mathrm{rs}}\left(u_{\mathrm{r} y}-u_{\mathrm{s} y}\right)=0 .
\end{aligned}
$$

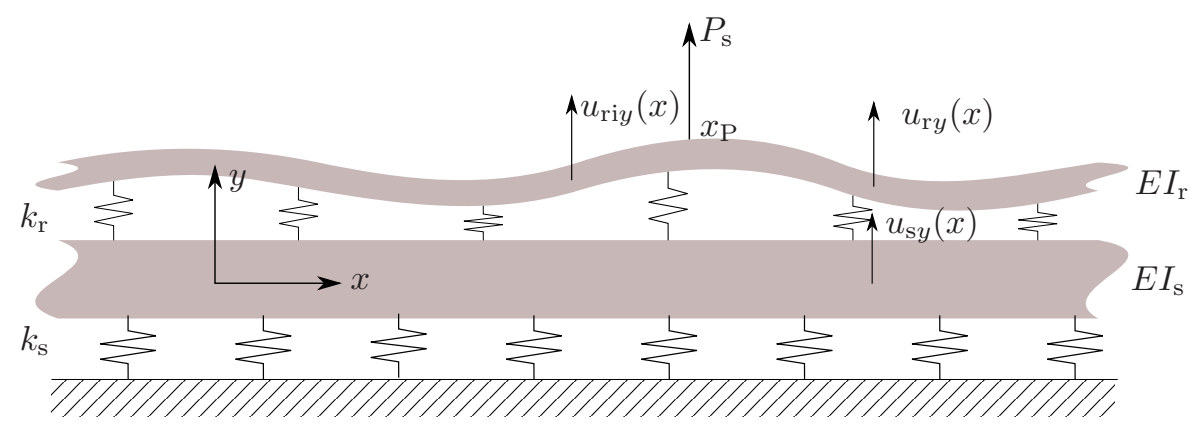

Figure 5: FST with bent rail unevenness $u_{\text {riy }}(x)$.

The equilibrium equations in the wavenumber domain are:

$$
\left[\begin{array}{cc}
k_{x}^{4}+\alpha_{\mathrm{rr}} & -\alpha_{\mathrm{rr}} \\
-\alpha_{\mathrm{rs}} & k_{x}^{4}+\alpha_{\mathrm{ss}}+\alpha_{\mathrm{rs}}
\end{array}\right]\left\{\begin{array}{c}
\tilde{u}_{\mathrm{r} y}\left(k_{x}\right) \\
\tilde{u}_{\mathrm{s} y}\left(k_{x}\right)
\end{array}\right\}=\left\{\begin{array}{c}
\frac{P_{\mathrm{s}}}{E I_{\mathrm{r}}} \mathrm{e}^{+\mathrm{j} k_{x} x_{\mathrm{P}}}+k_{x}^{4} \tilde{u}_{\mathrm{ri} y}\left(k_{x}\right) \\
0
\end{array}\right\} .
$$

The transfer function $\tilde{T}_{2 \mathrm{a}}\left(k_{x_{\mathrm{P}}}\right)$ between the bent rail unevenness $\tilde{u}_{\mathrm{ri} y}\left(k_{x_{\mathrm{P}}}\right)$ and the perceived unevenness $\tilde{u}_{2 \mathrm{a}}\left(k_{x_{\mathrm{P}}}\right)$ is equal to:

$$
\tilde{T}_{2 \mathrm{a}}\left(k_{x_{\mathrm{P}}}\right)=\frac{k_{x_{\mathrm{P}}}^{4}\left(\alpha_{\mathrm{rs}}+\alpha_{\mathrm{sS}}+k_{x_{\mathrm{P}}}^{4}\right)}{D\left(k_{x_{\mathrm{P}}}\right)}
$$

\subsection{Bent slab}

The slab can also have an initial deflection $u_{\text {siy }}(x)$ (figure 6). The bending moment in the slab is equal to $E I_{\mathrm{s}} \mathrm{d}^{2}\left(u_{\mathrm{s} y}-u_{\mathrm{si} y}\right) / \mathrm{d} x^{2}$, where $u_{\mathrm{s} y}-u_{\mathrm{si} y}$ is the deviation from the original deflected shape. The system of equilibrium equations becomes:

$$
\begin{aligned}
\frac{\mathrm{d}^{4} u_{\mathrm{r} y}}{\mathrm{~d} x^{4}}+\alpha_{\mathrm{rr}}\left(u_{\mathrm{r} y}-u_{\mathrm{s} y}\right) & =\frac{P_{\mathrm{s}}}{E I_{\mathrm{r}}} \delta\left(x-x_{\mathrm{P}}\right), \\
\frac{\mathrm{d}^{4}\left(u_{\mathrm{s} y}-u_{\mathrm{s} y}\right)}{\mathrm{d} x^{4}}+\alpha_{\mathrm{ss}} u_{\mathrm{s} y}-\alpha_{\mathrm{rs}}\left(u_{\mathrm{r} y}-u_{\mathrm{s} y}\right) & =0 .
\end{aligned}
$$




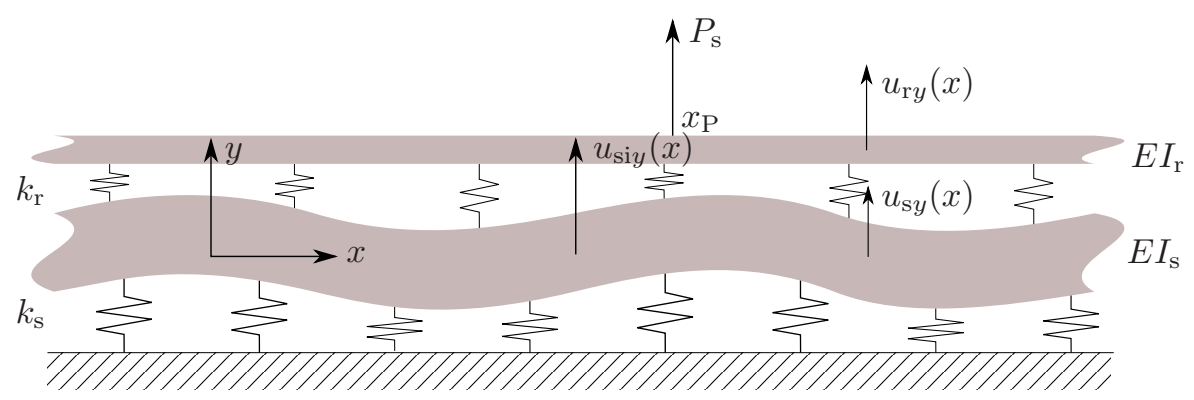

Figure 6: FST with bent slab unevenness $u_{\text {si } y}(x)$.

The equilibrium equations in the wavenumber domain are:

$$
\left[\begin{array}{cc}
k_{x}^{4}+\alpha_{\mathrm{rr}} & -\alpha_{\mathrm{rr}} \\
-\alpha_{\mathrm{rs}} & k_{x}^{4}+\alpha_{\mathrm{ss}}+\alpha_{\mathrm{rs}}
\end{array}\right]\left\{\begin{array}{c}
\tilde{u}_{\mathrm{r} y}\left(k_{x}\right) \\
\tilde{u}_{\mathrm{s} y}\left(k_{x}\right)
\end{array}\right\}=\left\{\begin{array}{c}
\frac{P_{\mathrm{s}}}{E I_{\mathrm{r}}} \mathrm{e}^{+\mathrm{j} k_{x} x_{\mathrm{P}}} \\
k_{x}^{4} \tilde{u}_{\mathrm{si} y}\left(k_{x}\right)
\end{array}\right\} .
$$

The transfer function $\tilde{T}_{2 \mathrm{~b}}\left(k_{x_{\mathrm{P}}}\right)$ between the bent slab unevenness $\tilde{u}_{\mathrm{si} y\left(k_{x_{\mathrm{P}}}\right)}$ and the perceived unevenness $\tilde{u}_{2 \mathrm{~b}}\left(k_{x_{\mathrm{P}}}\right)$ is equal to:

$$
\tilde{T}_{2 \mathrm{~b}}\left(k_{x_{\mathrm{P}}}\right)=\frac{k_{x_{\mathrm{P}}}^{4} \alpha_{\mathrm{rr}}}{D\left(k_{x_{\mathrm{P}}}\right)}
$$

\subsection{Variation of rail support stiffness}

The case of variation of rail support stiffness is more complicated since it is a type of parametric unevenness. The rail support stiffness $k_{\mathrm{r}}(x)$ is a function of the position $x$ along the beam (figure 7 ). The system of equilibrium equations becomes:

$$
\begin{aligned}
E I_{\mathrm{r}} \frac{\mathrm{d}^{4} u_{\mathrm{r} y}}{\mathrm{~d} x^{4}}+k_{\mathrm{r}}(x)\left(u_{\mathrm{r} y}-u_{\mathrm{s} y}\right) & =P_{\mathrm{s}} \delta\left(x-x_{\mathrm{P}}\right), \\
E I_{\mathrm{s}} \frac{\mathrm{d}^{4} u_{\mathrm{s} y}}{\mathrm{~d} x^{4}}+k_{\mathrm{s}} u_{\mathrm{s} y}-k_{\mathrm{r}}(x)\left(u_{\mathrm{r} y}-u_{\mathrm{s} y}\right) & =0 .
\end{aligned}
$$

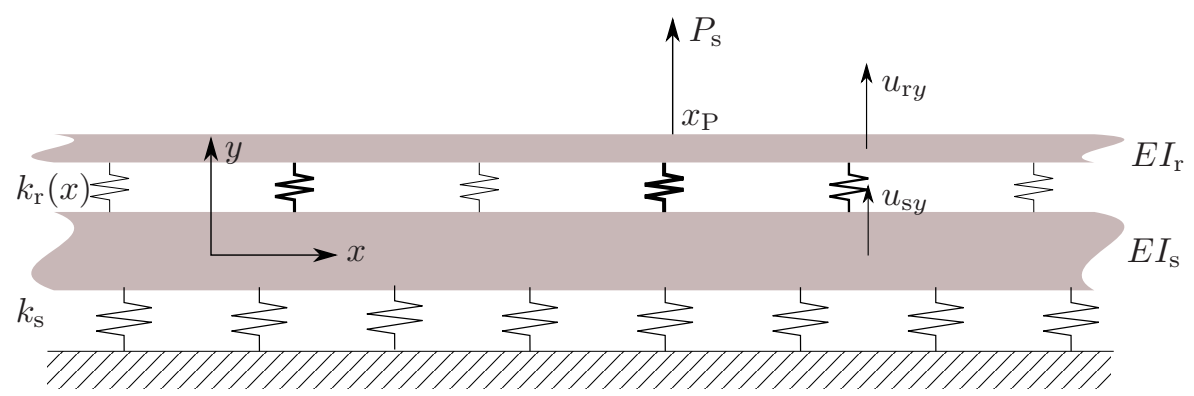

Figure 7: FST with variation of rail support stiffness $k_{\mathrm{r}}(x)$. 
Suppose that the rail pad stiffness can be expressed as the sum of a mean stiffness $k_{\mathrm{r} 0}$ and a small variation $\varepsilon w_{k_{\mathrm{r}}}(x) k_{\mathrm{r} 0}$ :

$$
k_{\mathrm{r}}(x)=\left(1+\varepsilon w_{k_{\mathrm{r}}}(x)\right) k_{\mathrm{r} 0}
$$

where $\varepsilon$ is a small constant and $w_{k_{\mathrm{r}}}(x)$ is a dimensionless function that represents the spatial variation of the rail pad stiffness $k_{\mathrm{r}}(x)$ about its mean value $k_{\mathrm{r} 0}$. The system of equilibrium equations can be rearranged as:

$$
\begin{aligned}
\frac{\mathrm{d}^{4} u_{\mathrm{r} y}}{\mathrm{~d} x^{4}}+\left(1+\varepsilon w_{k_{\mathrm{r}}}(x)\right) \alpha_{\mathrm{rr} 0}\left(u_{\mathrm{r} y}-u_{\mathrm{s} y}\right) & =\frac{P_{\mathrm{s}}}{E I_{\mathrm{r}}} \delta\left(x-x_{\mathrm{P}}\right), \\
\frac{\mathrm{d}^{4} u_{\mathrm{s} y}}{\mathrm{~d} x^{4}}+\alpha_{\mathrm{ss}} u_{\mathrm{s} y}-\left(1+\varepsilon w_{k_{\mathrm{r}}}(x)\right) \alpha_{\mathrm{r} \mathrm{s} 0}\left(u_{\mathrm{r} y}-u_{\mathrm{s} y}\right) & =0 .
\end{aligned}
$$

The products of the function $w_{k_{\mathrm{r}}}(x)$ with the displacements $u_{\mathrm{r} y}(x)$ and $u_{\mathrm{s} y}(x)$ prohibit a simple solution by means of the Fourier transform. Instead, an approximate solution is found using perturbation analysis, as elaborated in appendix A.

The transfer function $\tilde{T}_{3 \mathrm{a}}\left(k_{x_{\mathrm{P}}}\right)$ between the relative variation $\varepsilon \tilde{w}_{k_{\mathrm{r}}}\left(k_{x_{\mathrm{P}}}\right)$ of the rail support stiffness and the perceived unevenness $\tilde{u}_{3 \mathrm{a}}\left(k_{x_{\mathrm{P}}}\right)$ is equal to:

$$
\tilde{T}_{3 \mathrm{a}}\left(k_{x_{\mathrm{P}}}\right)=\frac{\alpha_{\mathrm{rr} 0}}{2 \pi} \frac{P_{\mathrm{s}}}{E I_{\mathrm{r}}} \int_{-\infty}^{\infty} \frac{k_{x}^{4}+\alpha_{\mathrm{ss}}}{D\left(k_{x}\right)} \frac{\left(k_{x}-k_{x_{\mathrm{P}}}\right)^{4}+\alpha_{\mathrm{sS}}}{D\left(k_{x}-k_{x_{\mathrm{P}}}\right)} \mathrm{d} k_{x} .
$$

This inverse wavenumber integral can be evaluated analytically using contour integration. In contrast to the previously derived transfer functions, this transfer function is proportional to the static axle load $P_{\mathrm{s}}$.

\subsection{Variation of slab bearing stiffness}

The variation of slab bearing stiffness $k_{\mathrm{s}}(x)$ is considered next (figure 8 ). The system of equilibrium equations is:

$$
\begin{aligned}
E I_{\mathrm{r}} \frac{\mathrm{d}^{4} u_{\mathrm{r} y}}{\mathrm{~d} x^{4}}+k_{\mathrm{r}}\left(u_{\mathrm{r} y}-u_{\mathrm{s} y}\right) & =P_{\mathrm{s}} \delta\left(x-x_{\mathrm{P}}\right), \\
E I_{\mathrm{s}} \frac{\mathrm{d}^{4} u_{\mathrm{s} y}}{\mathrm{~d} x^{4}}+k_{\mathrm{s}}(x) u_{\mathrm{s} y}-k_{\mathrm{r}}\left(u_{\mathrm{r} y}-u_{\mathrm{s} y}\right) & =0 .
\end{aligned}
$$

The slab support stiffness can be written as the sum of a mean stiffness $k_{\mathrm{s} 0}$ and a small variation $\varepsilon w_{k_{\mathrm{s}}}(x) k_{\mathrm{s} 0}$ :

$$
k_{\mathrm{s}}(x)=\left(1+\varepsilon w_{k_{\mathrm{s}}}(x)\right) k_{\mathrm{s} 0}
$$

where $\varepsilon$ is a small constant and $w_{k_{\mathrm{s}}}(x)$ is a dimensionless function that represents the spatial variation of 


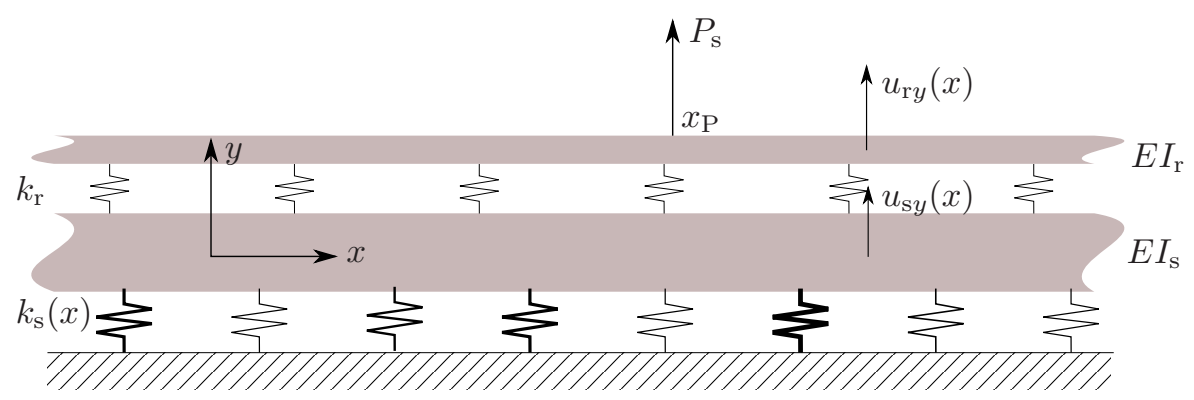

Figure 8: FST with variation of slab bearing stiffness $k_{\mathrm{r}}(x)$.

the slab bearing stiffness $k_{\mathrm{s}}(x)$ about its mean value $k_{\mathrm{s} 0}$. Following the same steps as for the rail support stiffness, the transfer function $\tilde{T}_{3 \mathrm{~b}}\left(k_{x_{\mathrm{P}}}\right)$ between the relative variation $\varepsilon \tilde{w}_{k_{\mathrm{s}}}\left(k_{x_{\mathrm{P}}}\right)$ of the slab bearing stiffness and the perceived unevenness $\tilde{u}_{3 \mathrm{~b}}\left(k_{x_{\mathrm{P}}}\right)$ is obtained as:

$$
\tilde{T}_{3 \mathrm{~b}}\left(k_{x_{\mathrm{P}}}\right)=\frac{\alpha_{\mathrm{rr}} \alpha_{\mathrm{ss} 0} \alpha_{\mathrm{rs}}}{2 \pi} \frac{P_{\mathrm{s}}}{E I_{\mathrm{r}}} \int_{-\infty}^{\infty} \frac{1}{D\left(k_{x}\right) D\left(k_{x}-k_{x_{\mathrm{P}}}\right)} \mathrm{d} k_{x} .
$$

This inverse wavenumber integral can be evaluated analytically using contour integration. The transfer function also linearly depends upon the static axle load $P_{\mathrm{s}}$.

\subsection{Variation of rail bending stiffness}

The procedure for dealing with a random variation of the rail bending stiffness $E I_{\mathrm{r}}(x)$ (figure 9$)$ is analogous to the procedure for random variation of the support stiffness. As $E I_{\mathrm{r}}(x)$ is not constant, the system of equilibrium equations becomes slightly more complicated:

$$
\begin{aligned}
E I_{\mathrm{r}} \frac{\mathrm{d}^{4} u_{\mathrm{r} y}}{\mathrm{~d} x^{4}}+2 \frac{\mathrm{d} E I_{\mathrm{r}}}{\mathrm{d} x} \frac{\mathrm{d}^{3} u_{\mathrm{r} y}}{\mathrm{~d} x^{3}}+\frac{\mathrm{d}^{2} E I_{\mathrm{r}}}{\mathrm{d} x^{2}} \frac{\mathrm{d}^{2} u_{\mathrm{r} y}}{\mathrm{~d} x^{2}}+k_{\mathrm{r}}\left(u_{\mathrm{r} y}-u_{\mathrm{s} y}\right) & =P_{\mathrm{s}} \delta\left(x-x_{\mathrm{P}}\right), \\
E I_{\mathrm{s}} \frac{\mathrm{d}^{4} u_{\mathrm{s} y}}{\mathrm{~d} x^{4}}+k_{\mathrm{s}} u_{\mathrm{s} y}-k_{\mathrm{r}}\left(u_{\mathrm{r} y}-u_{\mathrm{s} y}\right) & =0 .
\end{aligned}
$$

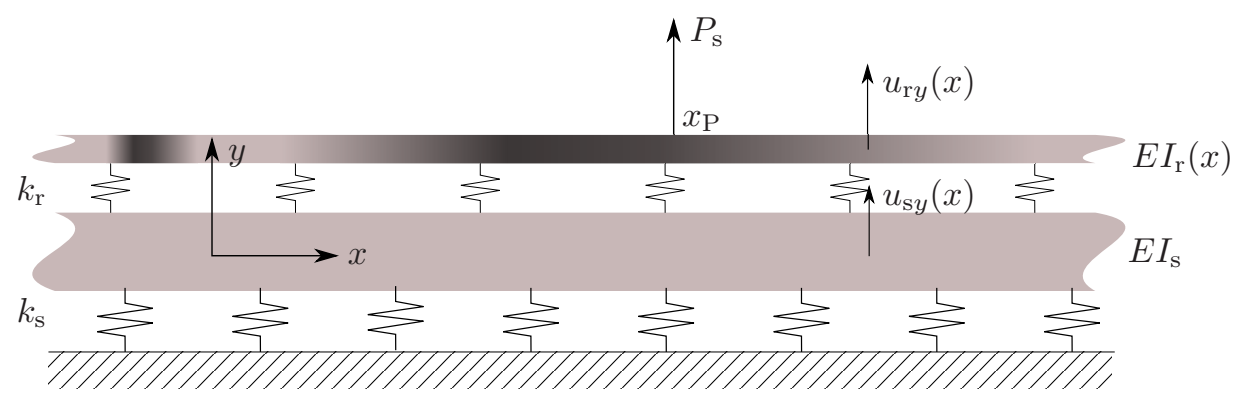

Figure 9: FST with variation of rail bending stiffness $E I_{\mathrm{r}}(x)$.

Suppose that the rail bending stiffness can be expressed as the sum of a mean value $E I_{\mathrm{r} 0}$ and a small 
variation $\varepsilon w_{E I_{\mathrm{r}}}(x) E I_{\mathrm{r} 0}$ :

$$
E I_{\mathrm{r}}(x)=\left(1+\varepsilon w_{E I_{\mathrm{r}}}(x)\right) E I_{\mathrm{r} 0},
$$

where $\varepsilon$ is a small constant and $w_{E I_{\mathrm{r}}}(x)$ is a dimensionless function that represents the spatial variation of the rail bending stiffness $E I_{\mathrm{r}}(x)$ about its mean value $E I_{\mathrm{r} 0}$. The perturbation analysis proceeds as before to obtain the transfer function $\tilde{T}_{4 \mathrm{a}}\left(k_{x_{\mathrm{P}}}\right)$ between the relative variation $\varepsilon \tilde{w}_{E I_{\mathrm{r}}}\left(k_{x_{\mathrm{P}}}\right)$ of the rail bending stiffness and the perceived unevenness $\tilde{u}_{4 \mathrm{a}}\left(k_{x_{\mathrm{P}}}\right)$ :

$$
\begin{aligned}
\tilde{T}_{4 \mathrm{a}}\left(k_{x_{\mathrm{P}}}\right)= & \frac{1}{2 \pi} \frac{P_{\mathrm{s}}}{E I_{\mathrm{r}}} \int_{-\infty}^{\infty} \frac{\left[\left(k_{x}-k_{x_{\mathrm{P}}}\right)^{4}+2 k_{x_{\mathrm{P}}}\left(k_{x}-k_{x_{\mathrm{P}}}\right)^{3}+k_{x_{\mathrm{P}}}^{2}\left(k_{x}-k_{x_{\mathrm{P}}}\right)^{2}\right]\left(k_{x}^{4}+\alpha_{\mathrm{rs}}+\alpha_{\mathrm{ss}}\right)}{D\left(k_{x}\right)} \\
& \frac{\left[\left(k_{x}-k_{x_{\mathrm{P}}}\right)^{4}+\alpha_{\mathrm{rs}}+\alpha_{\mathrm{ss}}\right]}{D\left(k_{x}-k_{x_{\mathrm{P}}}\right)} \mathrm{d} k_{x} .
\end{aligned}
$$

The inverse wavenumber integral can be evaluated analytically using contour integration. The transfer function linearly depends upon the static axle load $P_{\mathrm{s}}$.

\subsection{Variation of slab bending stiffness}

The influence of the variation of slab bending stiffness $E I_{\mathrm{s}}(x)$ (figure 10) can be studied analogously. The system of equilibrium equations is:

$$
\begin{aligned}
& E I_{\mathrm{r}} \frac{\mathrm{d}^{4} u_{\mathrm{r} y}}{\mathrm{~d} x^{4}}+k_{\mathrm{r}}\left(u_{\mathrm{r} y}-u_{\mathrm{s} y}\right)=P_{\mathrm{s}} \delta\left(x-x_{\mathrm{P}}\right),
\end{aligned}
$$

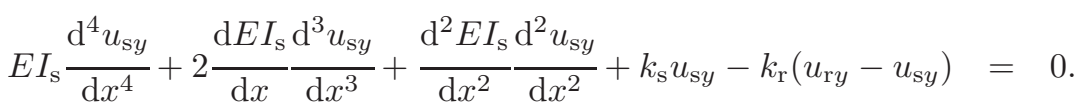

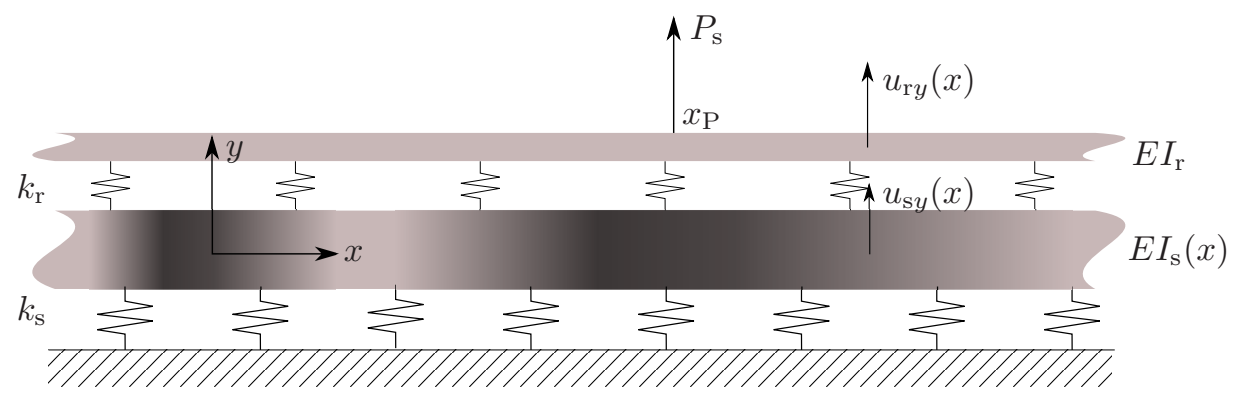

Figure 10: FST with variation of slab bending stiffness $E I_{\mathrm{S}}(x)$.

The transfer function $\tilde{T}_{4 \mathrm{~b}}\left(k_{x_{\mathrm{P}}}\right)$ between the relative variation $\varepsilon \tilde{w}_{E I_{\mathrm{s}}}\left(k_{x_{\mathrm{P}}}\right)$ of the slab bending stiffness and the perceived unevenness $\tilde{u}_{4 \mathrm{~b}}\left(k_{x_{\mathrm{P}}}\right)$ is equal to:

$$
\tilde{T}_{4 \mathrm{~b}}\left(k_{x_{\mathrm{P}}}\right)=\frac{\alpha_{\mathrm{rr}} \alpha_{\mathrm{rs}}}{2 \pi} \frac{P_{\mathrm{s}}}{E I_{\mathrm{r}}} \int_{-\infty}^{\infty} \frac{\left[\left(k_{x}-k_{x_{\mathrm{P}}}\right)^{4}+2 k_{x_{\mathrm{P}}}\left(k_{x}-k_{x_{\mathrm{P}}}\right)^{3}+k_{x_{\mathrm{P}}}^{2}\left(k_{x}-k_{x_{\mathrm{P}}}\right)^{2}\right]}{D\left(k_{x}\right) D\left(k_{x}-k_{x_{\mathrm{P}}}\right)} \mathrm{d} k_{x} .
$$


This inverse wavenumber integral can be evaluated analytically using contour integration. The transfer function is proportional to the static axle load $P_{\mathrm{s}}$.

\section{Case history: vibration mitigation on metro line M1 of ATM in Milan (Italy)}

\subsection{Track characteristics}

The transfer functions are evaluated for the track of metro line M1 of ATM in Milan (Italy) where, within the frame of the CONVURT project in 2003, rail fasteners on tangent track have been replaced by a flexible Pandrol Vanguard rail support system as to reduce vibration levels. The refurbished track is situated halfway between the Cadorna and Conciliazione stations, about $350 \mathrm{~m}$ west of Cadorna station, where a slab track supported by an elastic foundation is present in a shallow cut and cover tunnel with rectangular cross section. The track incorporates a simple form of FST and consists of two 50 UNI rails, supported every 0.8 $\mathrm{m}$ by grooved rubber rail pads. The slab is made of light concrete and is placed on neoprene strips which are laid every $0.50 \mathrm{~m}$ with polystyrene in between. The two rails are represented by a single beam in the model and the average stiffness of the rail and slab supports along the track are estimated. Damping in the structural elements is represented by loss factors. The track characteristics are summarized in table 2 .

Table 2: Track characteristics of metro line M1 of ATM in Milan (Italy).

\begin{tabular}{lcc}
\hline Property & Symbol & Value \\
\hline & & \\
Rail mass per unit length (2 rails) & $m_{\mathrm{r}}$ & $99.70 \mathrm{~kg} / \mathrm{m}$ \\
Rail bending stiffness (2 rails) & $E I_{\mathrm{r}}$ & $7.74 \mathrm{MNm}^{2}$ \\
Rail bending loss factor & $\eta_{E I_{\mathrm{r}}}$ & 0.02 \\
Rail pad stiffness per unit length (2 rails) & $k_{\mathrm{r}}$ & $1250 \mathrm{MN} / \mathrm{m}^{2}$ \\
Rail pad loss factor & $\eta_{k_{\mathrm{r}}}$ & 0.5 \\
Slab mass per unit length & $m_{\mathrm{s}}$ & $627 \mathrm{~kg} / \mathrm{m}^{2}$ \\
Slab bending stiffness & $E I_{\mathrm{s}}$ & $7.12 \mathrm{MNm}$ \\
Slab bending loss factor & $\eta_{E I_{\mathrm{s}}}$ & 0.05 \\
Slab support stiffness per unit length & $k_{\mathrm{s}}$ & $200 \mathrm{MN} / \mathrm{m}^{2}$ \\
Slab support loss factor & $\eta_{k_{\mathrm{s}}}$ & 0.5 \\
& & \\
\hline
\end{tabular}

\subsection{Unevenness transfer functions}

In order to assess the relative contribution of each unevenness source in the perceived unevenness, the input unevenness needs to be transformed to perceived unevenness using the transfer functions derived in section 3. Figure 11 shows the unevenness transfer functions as a function of the wavenumber $k_{x}$. For the four geometrical unevenness sources, this transfer function is dimensionless and gives a direct relation between the input unevenness and the perceived unevenness. For example, at $k_{x}=1 \mathrm{rad} / \mathrm{m}: \tilde{T}_{1 \mathrm{a}}=-0.4$ $\mathrm{dB}, \tilde{T}_{1 \mathrm{~b}}=-0.7 \mathrm{~dB}, \tilde{T}_{2 \mathrm{a}}=-27.6 \mathrm{~dB}$ and $\tilde{T}_{2 \mathrm{~b}}=-29.6 \mathrm{~dB}$. This means that a harmonic input unevenness 
profile with an amplitude of $1 \mathrm{~mm}$ results in perceived unevenness with an amplitude of $0.96,0.93,0.04$ and $0.03 \mathrm{~mm}$, respectively, for cases $1 \mathrm{a}$ to $2 \mathrm{~b}$. For the four parametric unevenness sources, however, the transfer function is not dimensionless. A stiffness variation of a track component results in a variation of the static rail deflection, which is perceived as unevenness. This deflection is proportional to the applied static axle load. Therefore, transfer functions $\tilde{T}_{3 \mathrm{a}}$ till $\tilde{T}_{4 \mathrm{~b}}$ are normalized by dividing by the static rail deflection $u_{\mathrm{r} y}^{0}\left(x_{P}\right)$ under the static axle load $P_{\mathrm{s}}$. For a MI79 service train, the static axle load is approximately equal to $P_{\mathrm{s}}=128 \mathrm{kN}$ and the resulting static rail deflection is equal to $u_{\mathrm{r} y}^{0}\left(x_{P}\right)=0.51 \mathrm{~mm}$. This small value is due to the presence of very stiff rail pads. The transfer functions for cases $3 \mathrm{a}$ to $4 \mathrm{~b}$ need to be interpreted in the following way: a harmonic variation of one of the stiffness elements with amplitude $\varepsilon$ and wavenumber $k_{x}$ results in a harmonic perceived unevenness profile with amplitude $\varepsilon \tilde{T}\left(k_{x}\right) u_{\mathrm{ry}}^{0}$. For example, at $k_{x}=1 \mathrm{rad} / \mathrm{m}$, the transfer functions, normalized to the static rail deflection $u_{\mathrm{r} y}^{0}\left(x_{P}\right)$, are $\tilde{T}_{3 \mathrm{a}}=-17.6 \mathrm{~dB}, \tilde{T}_{3 \mathrm{~b}}=-5.3 \mathrm{~dB}$, $\tilde{T}_{4 \mathrm{a}}=-16.2 \mathrm{~dB}$ and $\tilde{T}_{4 \mathrm{~b}}=-25.4 \mathrm{~dB}$. The resulting harmonic perceived unevenness due to an amplitude $\varepsilon=0.1$ is equal to of $6.8,27.8,7.9$ and $2.8 \mu \mathrm{m}$, respectively, for cases $3 \mathrm{a}$ to $4 \mathrm{~b}$.

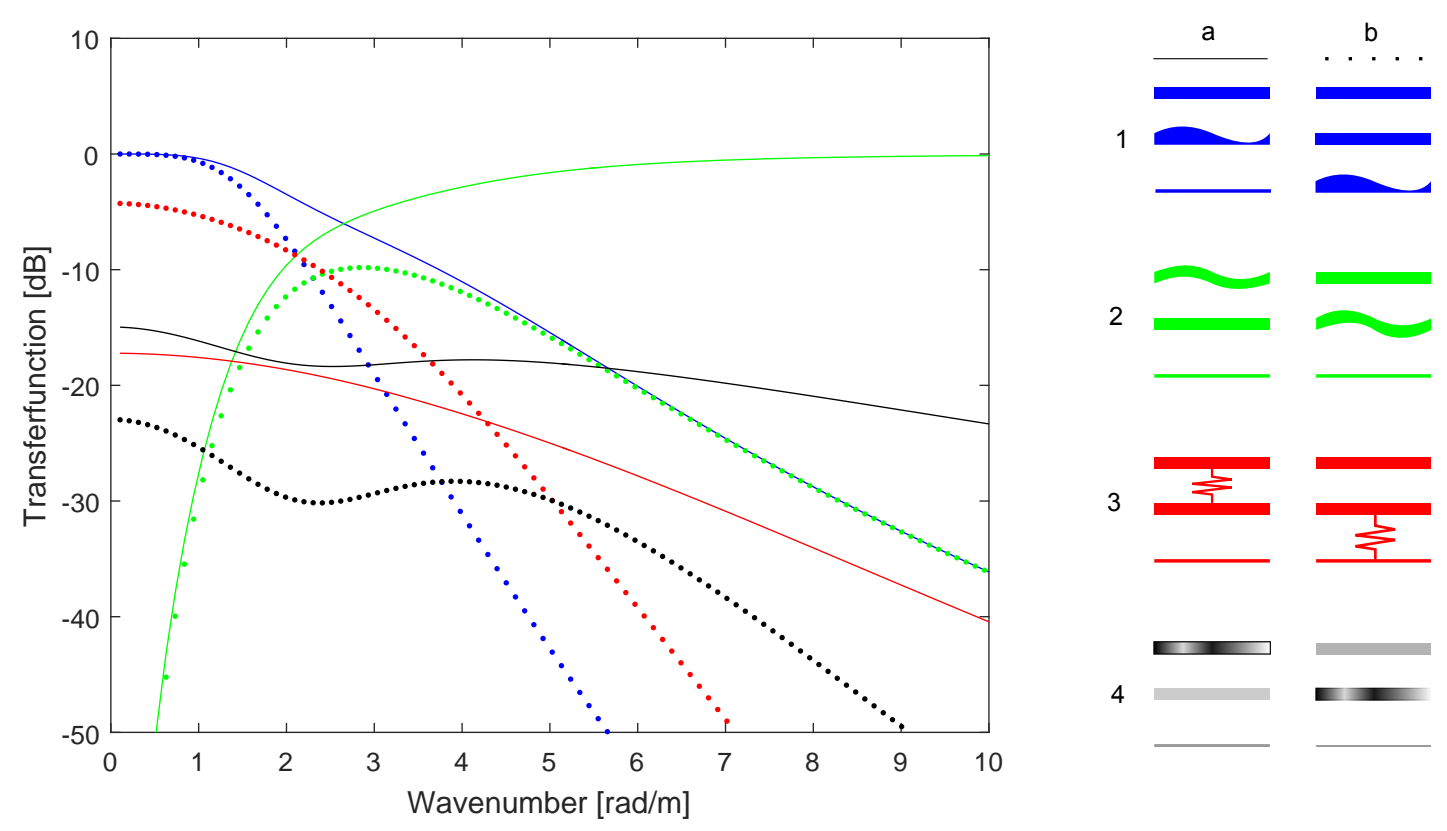

Figure 11: Unevenness transfer functions for slab (blue solid line) and track bed (blue dots) unevenness, bent rail (green solid line) and bent slab (green dots), variation of rail (red solid line) and slab (red dots) support stiffness and variation of rail (black solid line) and slab (black dots) bending stiffness. The transfer functions $\tilde{T}_{3 \mathrm{a}}$ till $\tilde{T}_{4 \mathrm{~b}}$ are normalized to the static rail deflection $u_{\mathrm{r} y}^{0}\left(x_{P}\right)$.

Some particular relations between the transfer functions for geometrical unevenness sources can also be observed in figure 11. The following relation holds between the transfer functions of slab unevenness and 
bent rail in equations $(21)$ and (29):

$$
\tilde{T}_{1 \mathrm{a}}\left(k_{x}\right)+\tilde{T}_{2 \mathrm{a}}\left(k_{x}\right)=1
$$

Slab unevenness $\tilde{u}_{\mathrm{t} y}\left(k_{x}\right)$ is perceived as $\tilde{T}_{1 \mathrm{a}}\left(k_{x}\right) \tilde{u}_{\mathrm{t} y}\left(k_{x}\right)$. In the specific case where the rail is bent with the same profile $\tilde{u}_{\mathrm{t} y}\left(k_{x}\right)$, the forces in the rail pads are zero everywhere and the rails are not straigthened by the rail pads. The bent rail is perceived as $\tilde{T}_{2 \mathrm{a}}\left(k_{x}\right) \tilde{u}_{\mathrm{t} y}\left(k_{x}\right)$. Multiplication of equation $(51)$ by $\tilde{u}_{\mathrm{t} y}\left(k_{x}\right)$ then expresses that slab unevenness and (equally) bent rail are perceived together as the originating slab unevenness $\tilde{u}_{\mathrm{t} y}\left(k_{x}\right)$.

For the transfer functions of slab unevenness, track bed unevenness, and bent slab in equations (21), (29) and (33), the following relation holds:

$$
\tilde{T}_{1 \mathrm{a}}\left(k_{x}\right)=\tilde{T}_{1 \mathrm{~b}}\left(k_{x}\right)+\tilde{T}_{2 \mathrm{~b}}\left(k_{x}\right) .
$$

Slab unevenness $\tilde{u}_{\mathrm{ty}}\left(k_{x}\right)$ is perceived as $\tilde{T}_{1 \mathrm{a}}\left(k_{x}\right) \tilde{u}_{\mathrm{t} y}\left(k_{x}\right)$. Track bed unevenness with the same unevenness profile $\tilde{u}_{\mathrm{t} y}\left(k_{x}\right)$ is perceived as $\tilde{T}_{2 \mathrm{~b}}\left(k_{x}\right) \tilde{u}_{\mathrm{t} y}\left(k_{x}\right)$. In the specific case where the slab bends to the same unevenness $\tilde{u}_{\mathrm{t} y}\left(k_{x}\right)$ as the track bed, the forces in the slab support are zero everywhere and the slab is not straigthened by the slab support. Multiplication of equation $(52)$ by $\tilde{u}_{t y}\left(k_{x}\right)$ then expresses that the perceived unevenness due to the combination of bent slab and track bed unevenness is identical to the perceived unevenness due to slab unevenness.

The behaviour of the transfer functions in different wavenumber ranges is investigated in the following paragraphs.

At small wavenumbers $\left(k_{x}<1.5 \mathrm{rad} / \mathrm{m}\right)$ or long wavelengths, the transfer function $\tilde{T}_{1 \mathrm{a}}\left(k_{x}\right)$ for slab unevenness tends to 1.0 ( or $0 \mathrm{~dB}$ ), while according to equation $(51)$, the transfer function $\tilde{T}_{2 \mathrm{a}}\left(k_{x}\right)$ for bent rail tends to zero (or very low $\mathrm{dB}$ values). So, the rail bends to the slab unevenness. Furthermore, the transfer function $\tilde{T}_{1 \mathrm{~b}}\left(k_{x}\right)$ for track bed unevenness tends to 1.0 , while the transfer functions $\tilde{T}_{2 \mathrm{a}}\left(k_{x}\right)$ and $\tilde{T}_{2 \mathrm{~b}}\left(k_{x}\right)$ for bent rail and bent slab both tend to zero according to equations (51) and (52). As a result, the rail bends to the slab unevenness, while the slab bends to the track bed unevenness: bent rail and bent slab unevenness are straightened by the rail pads and slab bearings, respectively, and not perceived. Parametric unevenness, such as variation of rail and slab support stiffness, is perceived most at small wavenumbers as the corresponding wavelength is much longer than the characteristic length of the deflection bowl. As the slab support stiffness is much lower than the rail pad stiffness, the static rail deflection is more influenced by the former. Therefore, a variation in slab support stiffness results in a higher variation of the static deflection, which is perceived as unevenness, than a variation of the rail support stiffness. Similarly, variation of rail bending stiffness is perceived more than variation of slab bending stiffness, since the former is the smallest.

At intermediate wavenumbers $\left(1.5 \mathrm{rad} / \mathrm{m}<k_{x}<5 \mathrm{rad} / \mathrm{m}\right)$, the transfer function $\tilde{T}_{2 \mathrm{a}}\left(k_{x}\right)$ for bent rail 
increases for increasing wavenumber $k_{x}$ and tends to filter out slab unevenness, according to equation (51). The transfer function $\tilde{T}_{2 \mathrm{~b}}\left(k_{x}\right)$ for bent slab becomes increasingly important with respect to the transfer function $\tilde{T}_{2 \mathrm{a}}\left(k_{x}\right)$ of track bed unevenness, according to equations (51) and (52). The track bed unevenness is no longer able to bend the slab. Bent rail and bent slab are increasingly perceived as the rail and slab supports are not able to straighten them. Parametric unevenness, such as variation in rail pad and slab bearing stiffness, is perceived less than at smaller wavenumbers.

At large wavenumbers $\left(k_{x}>5 \mathrm{rad} / \mathrm{m}\right)$ or short wavelengths, the transfer function $\tilde{T}_{2 \mathrm{a}}\left(k_{x}\right)$ for bent rail further increases and tends to 1 . The rail pads are not able to straighten the rail and bent rail becomes the most perceived unevenness. For all other cases, the perceived unevenness decreases with increasing wavenumber, because the rail pads can no longer pass the unevenness to the rails. Moreover, the stiff slab acts as a low wavenumber filter for unevenness below the slab, which explains why the transfer functions $\tilde{T}_{1 \mathrm{~b}}\left(k_{x}\right)$ and $\tilde{T}_{3 \mathrm{~b}}\left(k_{x}\right)$ for track bed unevenness and variation of slab support stiffness decrease the most with increasing wavenumber.

The previous observations can be summarised as follows. Slab and track bed unevenness are perceived most at small wavenumbers. Bent rail is increasingly perceived with increasing wavenumbers, whereas bent slab is only perceived at intermediate wavenumbers, where track bed unevenness is no longer perceived. Variation in rail and slab support stiffness and rail and slab bending stiffness are most important at small wavenumbers, where the wavelength is large compared to the characteristic length of the deflection bowl caused by a load. Because of the small rail deflection under the static axle loads, perceived unevenness due to parametric unevenness would be very small in this particular track. Only in the low wavenumber range, variation of slab support stiffness is possibly important. For tracks with higher static rail deflection, parametric unevenness will be more important, as is shown in the next section.

\subsection{Unevenness insertion gain}

Vibration countermeasures often include inserting resilient elements, such as soft rail pads, into the track. Resilient Pandrol Vanguard fasteners with a stiffness of $2.3 \mathrm{MN} / \mathrm{m}$ were inserted, resulting in a reduced average stiffness $k_{\mathrm{r}}^{\prime}=5.75 \mathrm{MN} / \mathrm{m}^{2}$ along the track. The unevenness transfer functions are affected by these vibration mitigation measures and so the total perceived unevenness is modified.

The insertion gain of perceived unevenness is defined as:

$$
\mathrm{IG}_{\Delta}=\frac{\Delta^{\prime}\left(k_{x}\right)}{\Delta\left(k_{x}\right)}=\frac{u_{\delta}^{\prime}\left(k_{x}\right)+\tilde{T}_{1 \mathrm{a}}^{\prime}\left(k_{x}\right) u_{\mathrm{f} y}\left(k_{x}\right)+\tilde{T}_{1 \mathrm{~b}}^{\prime}\left(k_{x}\right) u_{\mathrm{ty}}\left(k_{x}\right)+\cdots}{u_{\delta}\left(k_{x}\right)+\tilde{T}_{1 \mathrm{a}}\left(k_{x}\right) u_{\mathrm{f} y}\left(k_{x}\right)+\tilde{T}_{1 \mathrm{~b}}\left(k_{x}\right) u_{\mathrm{ty}}\left(k_{x}\right)+\cdots},
$$

where $u_{\delta}\left(k_{x}\right)$ represents the rail roughness and wheel out of roundness that are not further considered in this paper. If it can be assumed that the perceived unevenness before and after the insertion of vibration mitigation measures is dominated by the same unevenness source, the insertion gain of the perceived unevenness can be approximated by the ratio of the transfer functions of this dominant unevenness source. 
This approximation allows to define an insertion gain function for each individual source of unevenness.
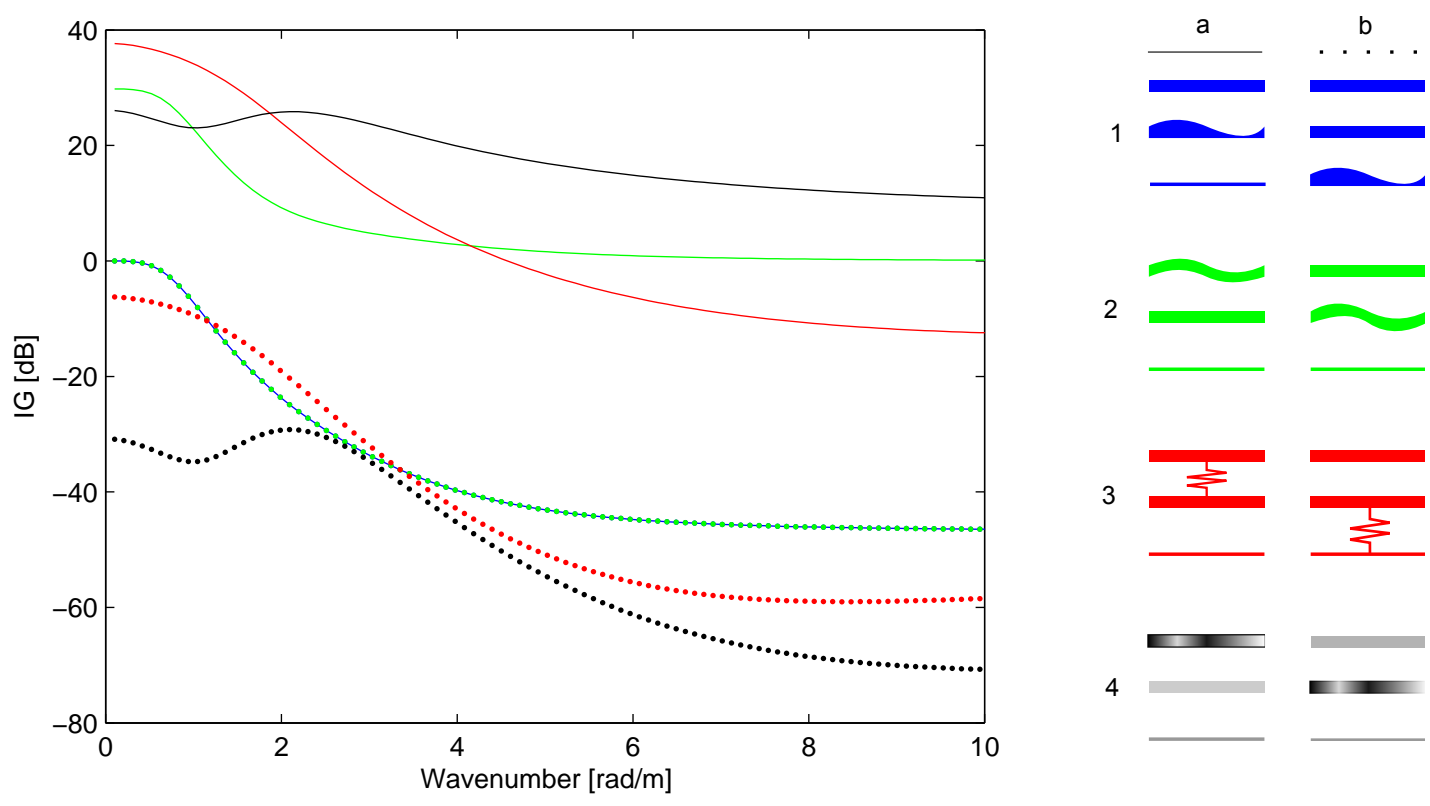

Figure 12: Unevenness insertion gain functions after installation of resilient rail supports for slab (blue solid line) and track bed (blue dots) unevenness, bent rail (green solid line) and bent slab (green dots), variation of rail (red solid line) and slab (red dots) support stiffness and variation of rail (black solid line) and slab (black dots) bending stiffness.

Figure 12 shows the unevenness insertion gain functions after installation of resilient rail supports for each source of unevenness as a function of the wavenumber $k_{x}$. In the track model, it is assumed that both rails and the slab are continuously supported. In the particular case of metro line M1 of ATM, where the rail is discretely supported, track unevenness due to sources below the rails will only be perceived by a train if the wavelength is longer than twice the sleeper distance $d=0.8 \mathrm{~m}$. For unevenness below the rails with shorter wavelength, spatial aliasing occurs. Therefore, the unevenness insertion gain functions are only valid for wavenumbers below $k_{x \max }=\pi / d=3.93 \mathrm{rad} / \mathrm{m}$. In this range of wavenumbers, the continuous track model is a good representation of the periodically supported track. For a train speed of $52 \mathrm{~km} / \mathrm{h}$, this corresponds to frequencies below $9 \mathrm{~Hz}$. For a similar track with smaller sleeper distance or continuous rail support, the insertion gain functions would be valid upto larger wavenumbers.

It is observed that $\mathrm{IG}_{T_{1 \mathrm{a}}}=\mathrm{IG}_{T_{1 \mathrm{~b}}}=\mathrm{IG}_{T_{2 \mathrm{~b}}}$, demonstrating that the change of perceived unevenness due to geometrical unevenness located below the vibration mitigation measure is independent of the source of unevenness. Due to the construction process, slab unevenness is a combination of slab and track bed unevenness, bent slab and shims.

At wavenumbers smaller than $0.5 \mathrm{rad} / \mathrm{m}$, the insertion gain of the perceived unevenness is constant for all types of unevenness. A large increase of unevenness is caused by bent rail, variation of rail support stiffness and variation of rail bending stiffness. Slab unevenness does not result in a change of perceived 
unevenness, while a variation of slab support stiffness and slab bending stiffness result in a decrease in perceived unevenness.

For wavenumbers higher than $0.5 \mathrm{rad} / \mathrm{m}$, the insertion gain of the perceived unevenness tends to an asymptotic value. For a variation of rail bending stiffness, the insertion gain remains positive. For bent rail, there is no change in perceived unevenness at large wavenumbers. For variation of rail support stiffness, the insertion gain varies from positive values at small wavenumbers to negative values at large wavenumbers. For slab unevenness, the insertion gain tends to a value of $20 \log k_{r}^{\prime} / k_{r}=-46.7 \mathrm{~dB}$. For variation of slab support stiffness and slab bending stiffness, the insertion gain is even lower.

If the unevenness is located below the inserted resilient element, unevenness smoothing occurs, as it is no longer transferred to the rails. In the case of geometrical unevenness, this is explained as follows. If the rail pads are stiff, the rails are bent in order to align with the much stiffer uneven slab. If the rail pad stiffness is reduced, however, coupling between the rails and the slab reduces and the rail bending stiffness prevents the rails to align with the uneven slab. Therefore, the perceived unevenness due to slab unevenness is smoothed. The perceived unevenness due to parametric unevenness is smoothed in a similar way. If the rail pads are very stiff, the rail deflection is determined by a combination of slab bearing and slab bending stiffness, and rail pad stiffness and rail bending stiffness. If the rail pad stiffness is reduced, coupling between the rails and the slab decreases. Less slab bending and slab bearing stiffness is mobilised and the deflection is mainly determined by the rail pad stiffness and rail bending stiffness. Therefore, perceived unevenness due to variations in slab bearing and slab bending stiffness is smoothed.

If the unevenness is situated above the resilient element, however, the latter may not be able to smooth the unevenness and an increase in perceived unevenness is possible. In the case of geometrical unevenness, this is explained as follows. If the rail pads are stiff then the initially bent rail is straightened in order to align with the much stiffer slab. If the rail pad stiffness is reduced, however, the rail bending stiffness prevents the rails to straighten and the unevenness due to bent rail increases. The perceived unevenness due to parametric unevenness increases in a similar way. If the rail pad stiffness is reduced, the rail deflection is primarily determined by the rail pad stiffness and rail bending stiffness. Therefore, perceived unevenness due to variations in rail pad stiffness and rail bending stiffness increase.

\subsection{Experimental results}

Vibration measurements were performed by Pandrol Limited on the east-bound track of metro line M1 ATM in Milan, about $350 \mathrm{~m}$ west of Codorna station, before and after installation of a flexible Pandrol Vanguard rail support system, less than two weeks apart [14]. These measurements were performed under operation of trains with a mean velocity of $v=52 \mathrm{~km} / \mathrm{h}$. Vibrations were measured on street level on the Via Gioberti, $10 \mathrm{~m}$ above the rail, using two PCB 393B12 seismic accelerometers; the first was installed approximately $20 \mathrm{~m}$ from the track center line and the second $10 \mathrm{~m}$ further along Via Gioberti. Figure 13 


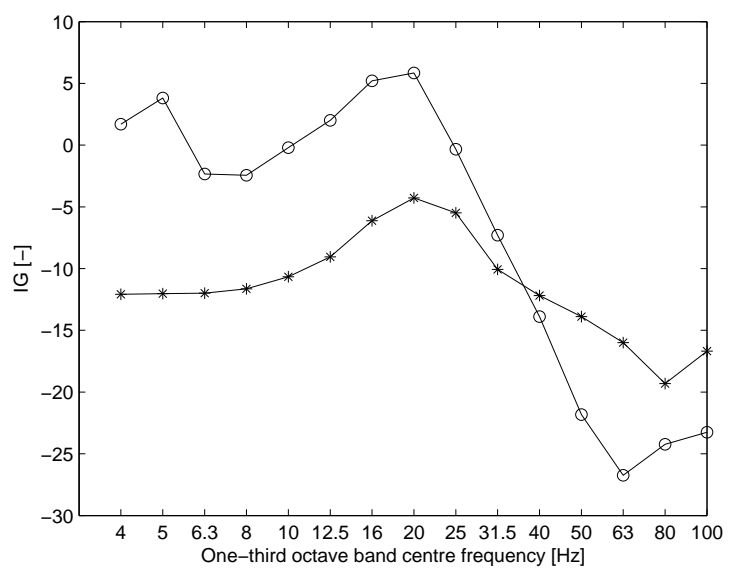

Figure 13: Insertion gain of the measured surface velocity (asterisks) and the computed transmitted force (circles) during the passage of a MI79 train as a function of the one-third octave band frequency after installation of the resilient rail support.

shows the insertion gain of the measured surface velocity in one-third octave bands after installation of the resilient rail support. Negative insertion gain denotes a reduced surface velocity and is observed through the whole frequency range under consideration. The largest reduction is obtained at the $80 \mathrm{~Hz}$ one-third octave band and the smallest at the $20 \mathrm{~Hz}$ one-third octave band. It is shown further that this is due to the shift of the first resonance frequency of the FST. The efficiency of the mitigation measure is analytically assessed through analysis of the force transmitted to the tunnel invert. Results of these computatations are compared with the measured insertion gain of the surface vibrations.

\subsection{Dynamic analysis}

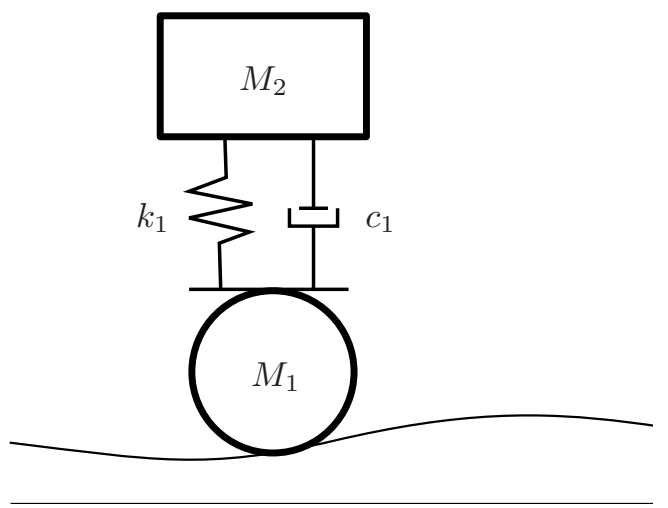

Figure 14: Two-degree-of-freedom model of a train representing an unsprung axle mass and half of a suspended bogie.

In order to compute the dynamic axle loads, a simplified two-degree-of-freedom model of a train shown in figure 14, also used by Hussein [27], is used, including an unsprung axle mass $M_{1}$, the primary suspension with stiffness $k_{1}$ and damping $c_{1}$, and half of a bogie with mass $M_{2}$; a comparative study of Costa et al. 
[28] revealed that a model which takes into account the wheelsets, the bogies and the primary suspensions is sufficiently accurate for the prediction of the response of the track and the free field. The wheelset and rails are often connected by a non-linear or a linearized Hertz spring in order to account for contact deformation $[29,30]$. Wu and Thompson [31] showed, however, that, at frequencies below $100 \mathrm{~Hz}$, wheel and track receptance are much larger than the receptance of the Hertzian contact spring, so that the latter can be regarded as effectively rigid and perfect contact between the wheelset and the rails can be assumed.

When an axle moves with speed $v$ over a sinusoidal track unevenness with wavelength $\lambda_{x}=2 \pi / k_{x}$ and amplitude $\Delta\left(k_{x}\right)$, the dynamic axle load $\hat{P}_{\mathrm{e}}(\omega)$ is computed by pulling the unevenness between the wheels and the rails and expressing the dynamic equilibrium of the axle mass [22]:

$$
\hat{P}_{\mathrm{e}}(\omega)=\frac{-\hat{R}_{1}(\omega)^{-1}}{1+\hat{R}_{1}(\omega)^{-1} \hat{H}_{\mathrm{yr}}(\omega)} \Delta(\omega / v)=\hat{H}_{1}(\omega) \Delta(\omega / v)
$$

where $\omega=v k_{x}$ is the excitation frequency, $\hat{H}_{\mathrm{yr}}(\omega)$ is the rail receptance, and $\hat{R}_{1}(\omega)$ is the axle receptance:

$$
\hat{R}_{1}(\omega)=\left(-\omega^{2} M_{1}-\frac{\omega^{2} M_{2}\left(k_{1}+\mathrm{j} \omega c_{1}\right)}{k_{1}+\mathrm{j} \omega c_{1}-\omega^{2} M_{2}}\right)^{-1}
$$

The rail receptance $\hat{H}_{\mathrm{yr}}(\omega)$ is derived in appendix B by solving the equilibrium equations (1) and (2) for the double beam model on rigid foundation, where the inertia of the rails and the slab is accounted for and hysteric damping in the rails and the slab is represented in the frequency domain by complex stiffness coefficients $k_{\mathrm{r}}^{*}=k_{\mathrm{r}}\left(1+\mathrm{j} \eta_{k_{\mathrm{r}}}\right)$ and $E I_{\mathrm{s}}^{*}=E I_{\mathrm{s}}\left(1+\mathrm{j} \eta_{E I_{\mathrm{s}}}\right)$, where $\eta_{k_{\mathrm{r}}}$ and $\eta_{E I_{\mathrm{s}}}$ are loss factors.

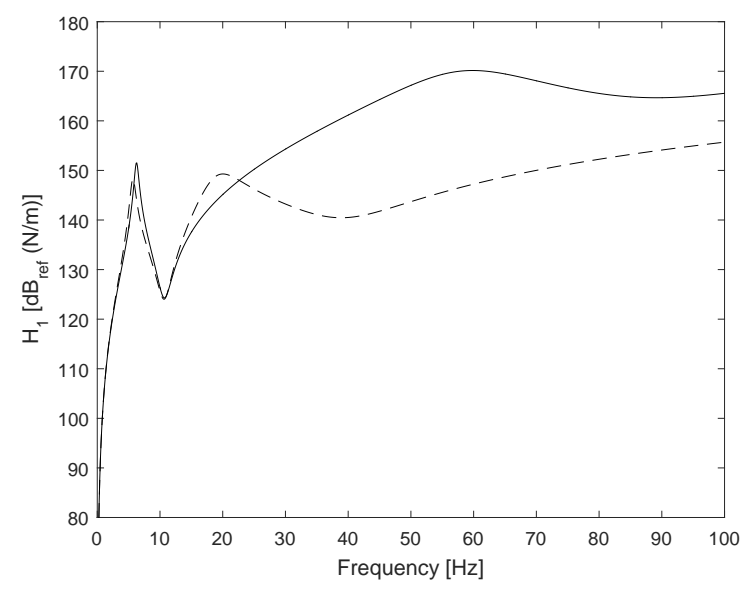

Figure 15: Transfer function $\hat{H}_{1}(\omega)$ between the perceived unevenness $\Delta(\omega / v)$ and the dynamic axle load $\hat{P}_{\mathrm{e}}(\omega)$ before (full line) and after (dashed line) the installation of the resilient rail support.

Figure 15 shows the transfer function $\hat{H}_{1}(\omega)$ between the perceived unevenness $\Delta(\omega / v)$ and the dynamic 
Table 3: Dynamic characteristics of a MI79 train.

\begin{tabular}{lcc}
\hline Property & Symbol & Value \\
\hline & & \\
Unsprung axle mass & $M_{1}$ & $1350 \mathrm{~kg}$ \\
Half bogie mass & $M_{2}$ & $3550 \mathrm{~kg}$ \\
Primary suspension stiffness & $k_{1}$ & $4000 \mathrm{kN} / \mathrm{m}$ \\
Primary suspension damping & $c_{1}$ & $10460 \mathrm{Ns} / \mathrm{m}$ \\
& & \\
\hline
\end{tabular}

axle load $\hat{P}_{\mathrm{e}}(\omega)$ before and after the installation of the resilient rail support, during the passage of a MI79 train. The dynamic characteristics of the train are summarized in table 3. Both curves exhibit a peak at $6 \mathrm{~Hz}$, which corresponds to the resonance mode of the bogie on the primary suspension. The second peak in the transfer function of the original track around $60 \mathrm{~Hz}$ corresponds to the resonance frequency of the unsprung mass on the track. Insertion of resilient rail supports leads to a large reduction of the excitation force at frequencies higher than $22 \mathrm{~Hz}$, with the largest reduction at $54 \mathrm{~Hz}$, due to a shift of the resonance peak to $20 \mathrm{~Hz}$, which also results in an increase of the excitation force at frequencies between 11 and $22 \mathrm{~Hz}$. At lower frequencies, there is a small shift in the resonance peak corresponding to the vibration mode of the bogie. At limiting low frequencies, no change in excitation force occurs, as the transfer function $\hat{H}_{1}(\omega)$ asymptotically does not depend on the track characteristics.

The force $\hat{P}_{\mathrm{t}}(\omega)$ transmitted to the tunnel invert can be calculated by integrating the deflection of the slab along the track and multiplying the result with the slab support stiffness. It can be demonstrated that this force is equal to the transmitted force of a track with infinite rail and slab bending stiffness [32]:

$$
\hat{P}_{\mathrm{t}}(\omega)=\frac{k_{\mathrm{r}}^{*} k_{\mathrm{s}}^{*}}{\left(-\omega^{2} m_{\mathrm{r}}+k_{\mathrm{r}}^{*}\right)\left(-\omega^{2} m_{\mathrm{s}}+k_{\mathrm{s}}^{*}\right)-k_{\mathrm{r}}^{*} \omega^{2} m_{\mathrm{r}}} \hat{P}_{\mathrm{e}}(\omega)=\hat{H}_{2}(\omega) \hat{P}_{\mathrm{e}}(\omega),
$$

where $\hat{H}_{2}(\omega)$ is the transfer function between the excitation force $\hat{P}_{\mathrm{e}}(\omega)$ and the transmitted force $\hat{P}_{\mathrm{t}}(\omega)$.

Figure 16 shows the transfer function $\hat{H}_{2}(\omega)$ before and after the installation of the resilient rail support. The transfer function of the original track exhibits a peak at $83.5 \mathrm{~Hz}$, corresponding to the first resonance frequency of the track, defined by the mass of the slab and the rails and the flexible slab support; the rail mass must be added to the slab mass because of the very stiff rail pads. After installation of the flexible Vanguard rail support system, the slab is uncoupled from the rail; the small bump at $89.9 \mathrm{~Hz}$ corresponds to the resonance frequency of the slab on its support. Due to the insertion of the resilient rail support, the transmitted force is reduced at frequencies higher than $52 \mathrm{~Hz}$. At lower frequencies, the transmitted force is increased, with a peak at $38.2 \mathrm{~Hz}$, corresponding to the resonance frequency of the rails supported by the Vanguard fasteners. At limiting low frequencies, the transmitted force is equal to the excitation force, as in the static case. 


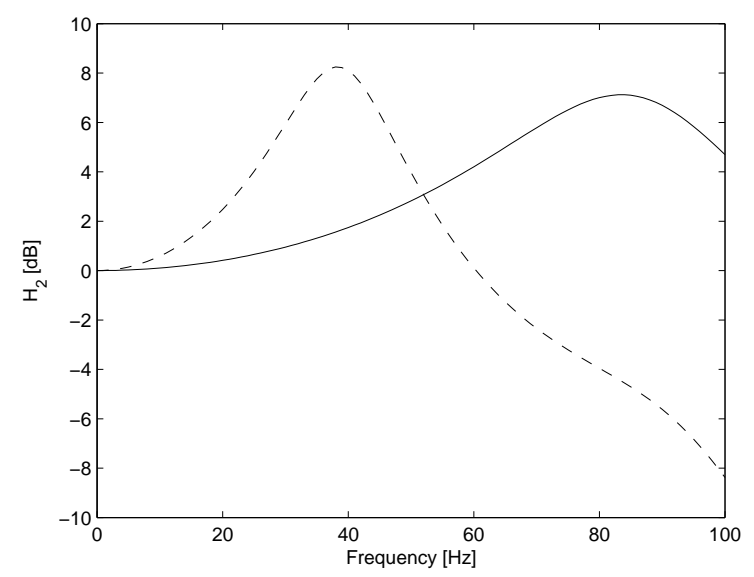

Figure 16: Transfer function $\hat{H}_{2}(\omega)$ between the excitation force $\hat{P}_{\mathrm{e}}(\omega)$ and the transmitted force $\hat{P}_{\mathrm{t}}(\omega)$ before (full line) and after (dashed line) the installation of the resilient rail support.

Combining equations (54) and (56), the force $\hat{P}_{\mathrm{t}}(\omega)$ transmitted to the tunnel invert is related to the unevenness $\Delta(\omega / v)$ as:

$$
\hat{P}_{\mathrm{t}}(\omega)=\hat{H}_{1}(\omega) \hat{H}_{2}(\omega) \Delta(\omega / v)
$$

To calculate the performance of the vibration countermeasure, the transmitted force can be calculated before and after modification of the track characteristics. The insertion gain $\mathrm{IG}_{\mathrm{t}}(\omega)$ of the force transmitted to the tunnel invert is a good measure for the insertion gain of the generated vibration levels, because of the weak coupling between the tunnel and the track, and equal to:

$$
\mathrm{IG}_{\mathrm{t}}(\omega)=\frac{\hat{P}_{\mathrm{t}}^{\prime}(\omega)}{\hat{P}_{\mathrm{t}}(\omega)}=\frac{\hat{H}_{1}^{\prime}(\omega) \hat{H}_{2}^{\prime}(\omega) \Delta^{\prime}(\omega / v)}{\hat{H}_{1}(\omega) \hat{H}_{2}(\omega) \Delta(\omega / v)}
$$

where the prime denotes the situation after the installation of the vibration mitigation measure. In equation (58), the interaction between different axles is not accounted for.

It is crucial to notice that the insertion gain $\operatorname{IG}_{\mathrm{t}}(\omega)$ not only depends upon changes in the transfer functions $\hat{H}_{1}(\omega)$ and $\hat{H}_{2}(\omega)$, but also upon changes in perceived track unevenness $\Delta(\omega / v)$.

Figure 13 also shows the insertion gain $\operatorname{IG}_{\mathrm{t}}(\omega)$ of the transmitted force during the passage of a MI79 train, due to the combined change of the transfer functions $\hat{H}_{1}(\omega)$ and $\hat{H}_{2}(\omega)$ after installation of the resilient rail support, but still neglecting the change in perceived unevenness $\Delta(\omega / v)$. At the $4 \mathrm{~Hz}$ and $5 \mathrm{~Hz}$ one-third octave bands, there is a small positive insertion gain, while a small negative insertion gain appears at the $6.3 \mathrm{~Hz}$ and $8 \mathrm{~Hz}$ one-third octave bands, due to a small shift of the bogie resonance peak. The latter is not observed in the insertion gain of the measured surface velocity, which may be due to higher damping than assumed in the model. Between the $10 \mathrm{~Hz}$ and $25 \mathrm{~Hz}$ one-third octave bands, the insertion gain is positive 
with a peak around $20 \mathrm{~Hz}$, predominantly due to a shift in the first axle-track resonance frequency, which is also observed for the measured surface velocities. At frequencies above the $25 \mathrm{~Hz}$ one-third octave band, there is a substantial reduction of the force transmitted to the tunnel invert, with a most favourable effect around the $63 \mathrm{~Hz}$ one-third octave band.

Even at the lowest frequencies, a decrease in measured velocity is observed, which cannot be explained by the modification of the dynamic track characteristics only, as the model predicts an increase in vibrations. In the prediction, the possible influence of the modified track characteristics on the perceived unevenness has not yet been accounted for. The measured and calculated insertion gains can be compared with the unevenness insertion gain functions presented in figure 12 , that are valid upto $k_{x \max }$, as explained before; the corresponding maximum excitation frequency at a train speed of $v=52 \mathrm{~km} / \mathrm{h}$ equals $f_{\max }=v / 2 d=9 \mathrm{~Hz}$. Figure 13 shows that in this frequency range, dynamic effects are negligible. Insertion gain of perceived unevenness (figure 12) on the other hand ranges from almost $40 \mathrm{~dB}$ at zero wavenumber for bent rail to $-45 \mathrm{~dB}$ for variation of slab bending stiffness at $k_{x \max }$. Depending on the unevenness source, both an increase or a decrease in perceived unevenness and, consequently, free field vibrations is possible. The observed decrease of measured vibration velocities of $-12 \mathrm{~dB}$ could be explained by a decrease of either slab unevenness, track bed unevenness, bent slab, variation of slab support stiffness or slab bending stiffness. It is therefore important to know which unevenness sources are probable to have contributed to the total perceived unevenness. Different scenarios will be investigated in the following section.

\section{Effect of unevenness sources on perceived unevenness}

\subsection{Identification and estimation of unevenness sources}

Track unevenness is usually characterized by a single-sided power spectral density (PSD). In order to estimate the perceived unevenness using the transfer functions derived in section 3 , estimates of input unevenness due to different sources are needed. Input unevenness, however, is often not measured (e.g. slab unevenness) or difficult to measure (e.g. variation of slab bending stiffness). Therefore, realistic estimates of the single-sided PSD of the input unevenness are made here based on available information from manufacturing and construction processes, as well as requirements defined in norms and standards.

During track construction, shims are placed under the rail pads in order to compensate for slab unevenness, track bed unevenness and bent slab, and to improve rail alignment. These unevenness sources can, thus, be treated together as perceived slab unevenness, measured above the shims. Due to the discrete rail support, the perceived slab unevenness is regarded as a discretely sampled random field with no correlation between different rail pad positions, characterized by the following single-sided PSD:

$$
S\left(k_{x}\right)=\frac{\sigma^{2} d}{\pi} \quad \text { for } \quad k_{x}<\frac{\pi}{d},
$$


where the variance $\sigma^{2}$ of the probability density function for a uniform distribution between $\pm a$ equals:

$$
\sigma^{2}=\frac{(2 a)^{2}}{12} \text {. }
$$

For slab unevenness characterized by $d=0.8 \mathrm{~m}$ and $a=0.5 \mathrm{~mm}$, characterizing optimal alignment with shims with a typical thickness of $1 \mathrm{~mm}$, the single-sided PSD and variance equal $S_{1 \mathrm{~b}}\left(k_{x}\right)=2.12 \times 10^{-8} \mathrm{~m}^{3}$ and $\sigma_{1 \mathrm{~b}}^{2}=8.33 \times 10^{-8} \mathrm{~m}^{2}$ according to equations (59) and (60).

Tolerance limits for rail straightness are defined in the British rail standard BS EN13674-1:2011 [33]. For class B rails (mass lower than $54 \mathrm{~kg} / \mathrm{m}$ ), a maximum gap of $0.3 \mathrm{~mm}$ under a ruler of $1 \mathrm{~m}$ and of $0.4 \mathrm{~mm}$ under a ruler of $3 \mathrm{~m}$ is allowed. Both requirements are satisfied if a maximum rail deflection of $\pm 0.2 \mathrm{~mm}$ is tolerated, without correlation for distances larger than $d$. For bent rail characterized by $d=0.8 \mathrm{~m}$ and $a=0.2 \mathrm{~mm}$, the single-sided PSD and variance equal $S_{2 \mathrm{a}}\left(k_{x}\right)=3.40 \times 10^{-9} \mathrm{~m}^{3}$ and $\sigma_{2 \mathrm{a}}^{2}=1.33 \times 10^{-8} \mathrm{~m}^{2}$ according to equations (59) and (60).

The different cooling history and straightening process (with rollers) of each rail may result into varying residual straightness or rail deflection, with dominant wavelengths varying between $1.8 \mathrm{~m}$ and $4 \mathrm{~m}$ and amplitudes of $0.6 \mathrm{~mm}$, depending on the manufacturer or production year [34]. These measurements were performed on rails in service, revealing the total perceived unevenness in unloaded condition, not accounting for parametic unevenness. Moreover, slab unevenness may have influenced the results, especially in the low wavenumber range, and should be accounted for. In order to measure bent rail unevenness before installation, the section of the rail, laying on its side, should preferably be measured. As no information on rail straightness of this particular track is available, the constant PSD is used, as explained above.

Rail pads within the same batch typically show a stiffness variance of a few percentage. Internal quality control on a batch of Pandrol 6530 rail pads showed a coefficient of variation of 0.035 [35]. Thompson and van Vliet [36] report a coefficient of variation of 0.09 on four nominally identical Swedish rail pads. In this paper, a coefficient of variation of 0.035 on the rail pad stiffness and different rail fastening systems is used. As rail pads are installed in random order to avoid any correlation between neighbouring rail pads, variation of rail pad stiffness can be represented by a single-sided PSD $S_{3 \mathrm{a}}\left(k_{x}\right)=3.06 \times 10^{-4} \mathrm{~m}$ that follows from equation (59) and a variance $\sigma_{3 \mathrm{a}}^{2}=0.035^{2}=0.0012$.

Pandrol CDM Track [37] reports a typical variation of slab bearing stiffness of $\pm 20 \%$. If it is assumed that this range corresponds to 6 standard deviations and that these stiffness variations are spatially uncorrelated, the variation of slab bearing stiffness is represented by a single-sided PSD $S_{3 \mathrm{~b}}\left(k_{x}\right)=0.0011 \mathrm{~m}$ that follows from equation (59) and a variance $\sigma_{3 \mathrm{~b}}^{2}=0.4^{2} / 6^{2}=0.0044$.

Variation in rail bending stiffness is expected to be negligible and is only included here because of its complementary to the more likely case of variation of slab bending stiffness. This is demonstrated by the following estimations. The height of a UNI 50 rail is $148 \mathrm{~mm}$. A variation of $1 \%$ of the rail bending 
stiffness may result from a height variation of about $0.5 \mathrm{~mm}$ or a same percentual (and relatively high) spatial variation of the Young's modulus. The maximum of the unevenness transfer function for variation in rail bending stiffness is about $-15 \mathrm{~dB}$ (figure 11). For a static deflection of $0.5 \mathrm{~mm}$, the perceived unevenness is equal to $0.89 \mu \mathrm{m}$, which is negligible compared to the geometrical unevenness of $0.5 \mathrm{~mm}$ on top of the rail. It can therefore be concluded that variation in rail bending stiffness is an unlikely source of perceived unevenness.

Variation in slab bending stiffness may be caused by cracks in the concrete, material heterogeneities and geometrical imperfections. These are very difficult to assess and no information on their spatial variation was obtained. As the unevenness transfer function is even lower than for the case of variation in rail bending stiffness, a relatively high variation of $10 \%$ of the slab bending stiffness only results in very small perceived unevenness of $3 \mu \mathrm{m}$.

\subsection{Practical relevance of perceived unevenness}

The total perceived uneveness results from the combination of different unevenness sources. If these are assumed to be uncorrelated, the single-sided PSD $S_{\Delta}\left(k_{x}\right)$ of the total perceived unevenness is obtained as [38]:

$$
S_{\Delta}\left(k_{x}\right)=S_{\delta}\left(k_{x}\right)+\left|\tilde{T}_{1 \mathrm{a}}\left(k_{x}\right)\right|^{2} S_{1 \mathrm{a}}\left(k_{x}\right)+\left|\tilde{T}_{1 \mathrm{~b}}\left(k_{x}\right)\right|^{2} S_{1 \mathrm{~b}}\left(k_{x}\right)+\ldots,
$$

where $S_{\delta}\left(k_{x}\right)$ is the single-sided PSD of the wheel and rail roughness $u_{\delta}(x)$, not considered in this paper. Every input unevenness in equation $(61)$ is characterized by its single-sided PSD $S\left(k_{x}\right)$, as identified in subsection 5.1, and multiplied by the corresponding transfer function $\tilde{T}\left(k_{x}\right)$, as determined in section 3 .

Figure 17 compares the contribution $\left|\tilde{T}\left(k_{x}\right)\right|^{2} S\left(k_{x}\right)$ to the total perceived unevenness $S_{\Delta}\left(k_{x}\right)$ of four types of unevenness for which estimates of the input PSD have been obtained in subsection 5.1, before installation of resilient rail supports: slab unevenness, bent rail, variation of rail and slab support stiffness. It was already concluded that slab unevenness, track bed unevenness and bent rail can be combined into one unevenness source and that the impact of variation of rail or slab bending stiffness is negligible.

Under the assumptions made in subsection 5.1, geometrical unevennes sources, and especially slab unevenness, are expected to have the highest contribution to the total perceived unevenness in the wavenumber range under consideration.

Bent rail has a very small influence at very low wavenumbers, but becomes more important with increasing wavenumber. The PSD of initial rail deflection was estimated to be smaller than the PSD of unevenness on top of the slab; due to the stiff rail pads, the initial rail deflections are straightened, while the unevenness on top of the slab is transferred to the rail.

The contribution of parametric unevenness sources as variation of rail and slab support stiffness is much lower, due to the small rail deflection under the static axle loads. In slab tracks with small static 
rail deflection, geometrical unevenness sources are dominant; very large variations of rail and slab support stiffness would be necessary to be relevant.

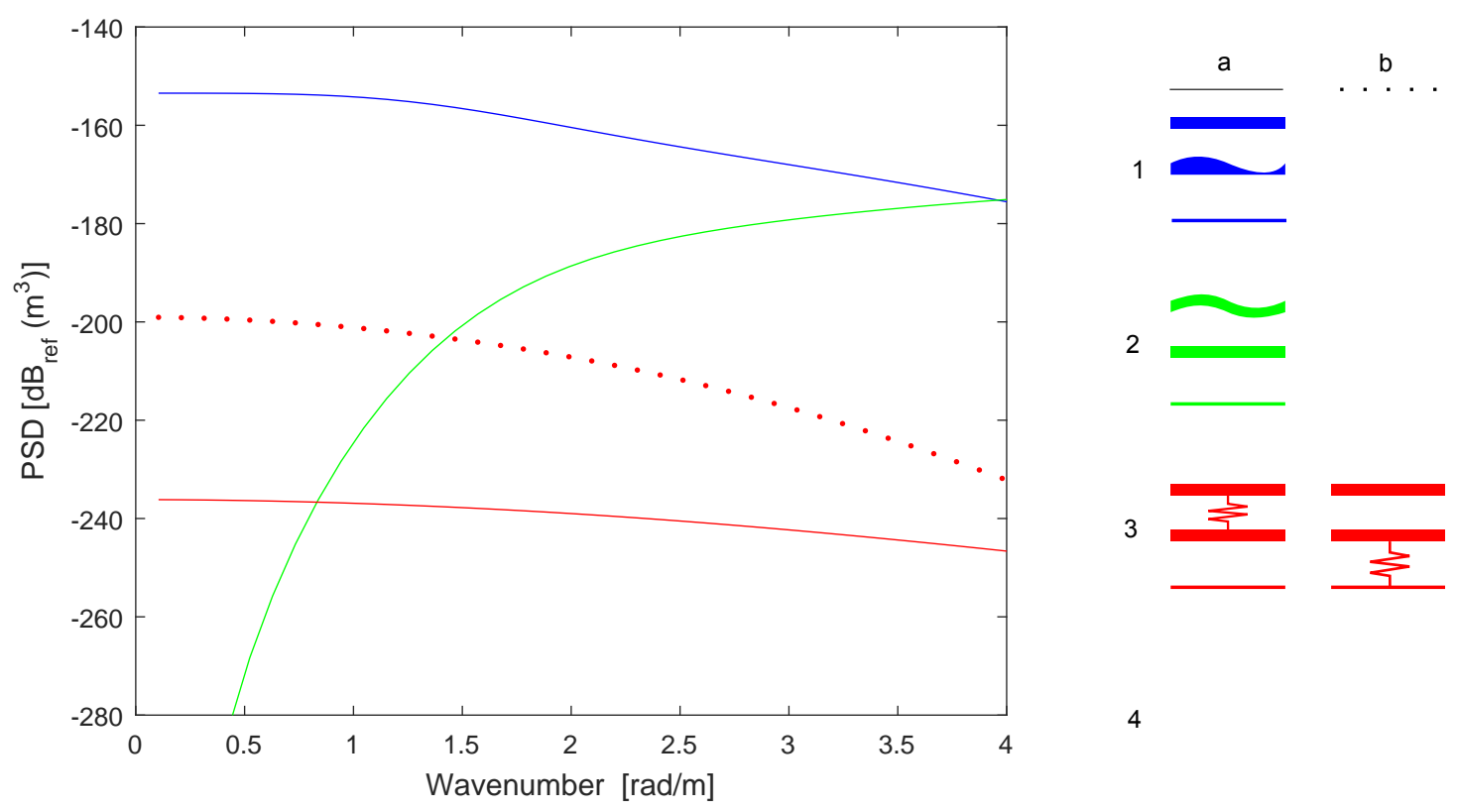

Figure 17: Single-sided PSD of perceived unevenness due to slab unevenness (blue solid line), bent rail (solid green line), variation of rail (red solid line) and slab (red dots) support stiffness, before installation of resilient rail supports.

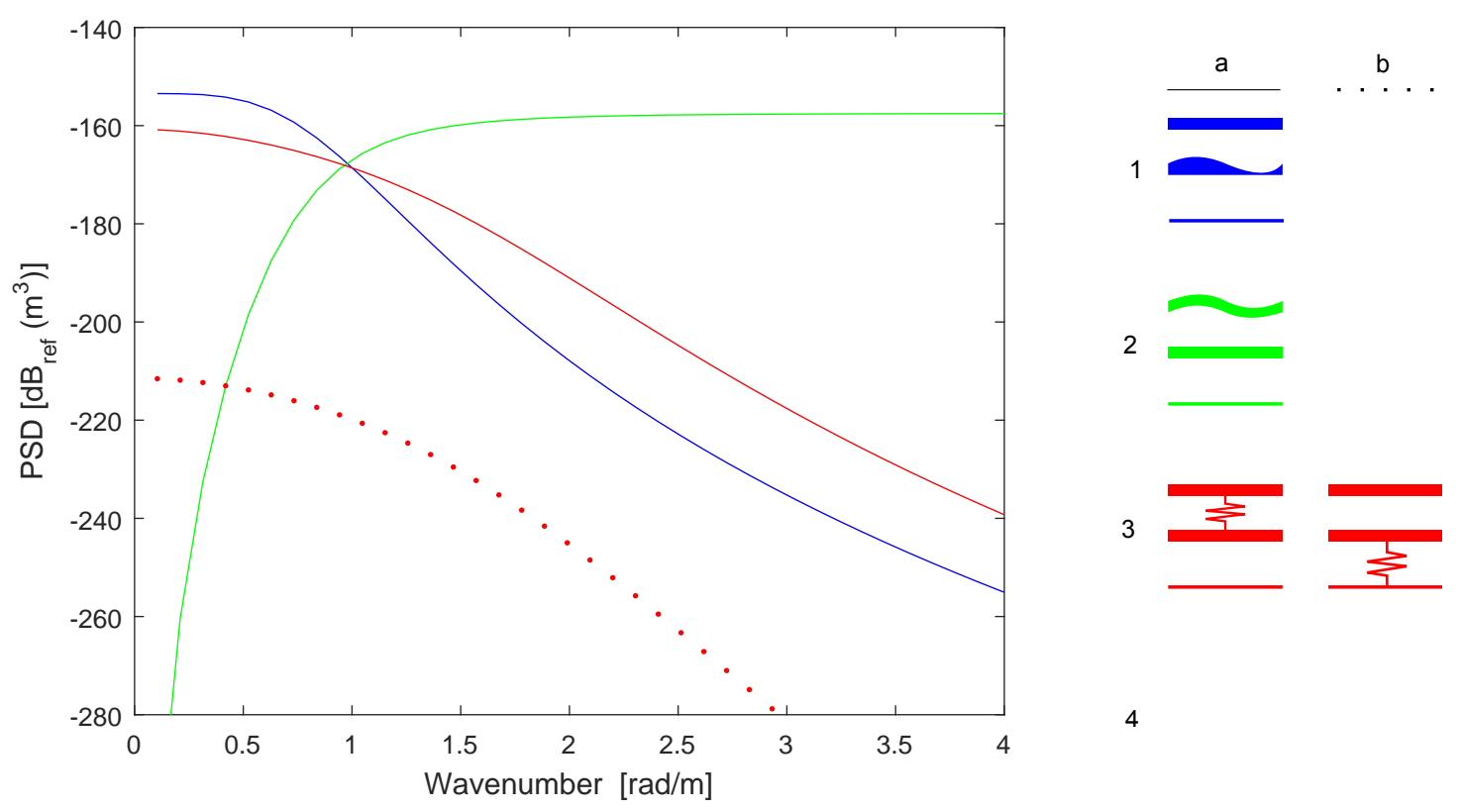

Figure 18: Single-sided PSD of perceived unevenness due to slab unevenness (solide blue line), bent rail (solid green line), variation of rail (red solid line) and slab (red dots) support stiffness, after installation of resilient rail supports. 
When modifying the dynamic track characteristics, the unevenness transfer functions are modified, as described in subsection 4.3, while it is assumed that the PSD of the unevenness sources remains unaffected. As a consequence, their contribution to the total perceived unevenness changes. Figure 18 shows the contribution $\left|\tilde{T}\left(k_{x}\right)\right|^{2} S\left(k_{x}\right)$ to the total perceived unevenness $S_{\Delta}\left(k_{x}\right)$ of the same four unevenness types, after installation of resilient rail supports.

Perceived unevenness due to slab unevenness much decreases, as predicted by the insertion gain functions in subsection 4.3. As slab unevenness is the most probable source of unevenness before installation of resilient rail supports, unevenness smoothing is very probable and, therefore, a likely explanation for the reduction of measured low frequency vibrations in the free field, as observed in figure 13.

Perceived unevenness due to bent rail much increases, as the soft rail supports are not able to compensate the initial rail deflection. However, since measured unevenness usually decreases with increasing wavenumber, it is likely that the PSD of bent rail unevenness at the higher wavenumbers is overestimated. This PSD is expected to be more concentrated around single wavenumbers characteristic for the manufacturing process [34]. These results show that it is important to control rail straightness and measure the total perceived unevenness after installation of in-track vibration countermeasures.

Variation of rail support stiffness was not a probable source of perceived unevenness prior to installation of resilient rail supports (figure 17), but is the second most probable unevenness source after track refurbishment (figure 18). The perceived unevenness increases at very low wavenumbers, as rail deflection is highly determined by the low vertical stiffness of the resilient rail supports; the average predicted rail deflection increases from $0.5 \mathrm{~mm}$ to $7.4 \mathrm{~mm}$. It is therefore important to limit the stiffness variation of the rail supports. It was shown in figure 12 that, at higher wavenumbers, perceived unevenness due to variation in rail support stiffness also results in unevenness smoothing. However, this only occurs for shorter sleeper distances or continuous rail support.

Perceived unevenness due to a variation of slab support stiffness reduces. As its contribution to the total perceived unevenness was already small before installation of resilient rail supports, it now is the least likely source of unevenness.

The foregoing conclusions hold for the particular case history investigated in this paper. Although realistic assumptions on the PSD of different unevenness sources were made, it was not possible to confirm these results by means of in situ measurements. Therefore, some unevenness sources may turn out to be more or less important than predicted, depending on the construction process and the track condition.

In other railway tracks, the relative importance of each of the considered sources of unevenness could be different. As a rule of thumb, geometrical unevenness sources are the most likely for stiff tracks with low static rail deflection. Nélain and Vincent [8] came to a similar conclusion for the particular case of a ballasted track. Typical variations of foundation stiffness were not found predominant over rail unevenness below the sleeper passing frequency. For tracks with resilient rail support and a larger static rail deflection, variation 
in rail support stiffness can also be important and needs to be limited. The effect of other parametric unevenness sources is negligible.

The results demonstrate that, depending on the source of unevenness, both an increase and decrease of perceived unevenness is possible after installation of resilient rail supports. Smoothing of unevenness sources located below the resilient element is very probable and a likely explanation for the often observed reduction of free field vibrations below half the sleeper passing frequency. In the case history presented in this paper with a train speed of $52 \mathrm{~km} / \mathrm{h}$ and a sleeper distance of $0.8 \mathrm{~m}$, this frequency equals $9 \mathrm{~Hz}$. For high speed trains and shorter sleeper distances, this frequency can increase to $45 \mathrm{~Hz}$. Similar conclusions were made by Hunt [9] for the case of a simply supported beam on a Winkler foundation.

This paper showed that slab unevenness and, to a lesser extent, stiffness variation of soft rail supports, are probable sources of unevenness that are reduced by installing resilient rail supports. Auersch [12] also predicted an important reduction of perceived track bed unevenness in the same wavenumber range as studied here. Measurements showed a reduction of vibration levels when comparing a slab track without and with under-sleeper pads in a mid frequency range where unevenness smoothing was predicted. Nélain et al. [7] predicted vibration reduction upto the sleeper passing frequency due to parametric unevenness related to broad band stiffness variation and sleeper periodicity. They further confirmed that in-track vibration mitigation measures can benefit from unevenness smoothing for low to medium frequencies, depending on the train speed.

Due to changes in perceived unevenness, it is impossible to predict changes in vibration levels if the dominant unevenness sources are not a priori known. Theoretical developments developed in this paper may help to assess the importance of different unevenness sources. It is also advised to measure as much as possible different types of unevenness when installing or testing in-track vibration countermeasures and to develop new techniques for this purpose. As it may not always be feasible to measure every type of unevenness, it remains important to measure at least the perceived unevenness before and after installation of in-track vibration countermeasures under different loading conditions, as to distinguish geometrical from parametric unevenness. These measurements are necessary to correctly assess the performance of vibration countermeasures. In order to check if a change in perceived unevenness is the dominant effect in low frequent vibration mitigation, the insertion gain of the free field vibrations should be compared with the insertion gain of the perceived unevenness.

\section{Conclusion}

Transfer functions have been derived between different sources of unevenness in a FST and the unevenness perceived by a moving train. Two types of perceived unevenness have been distinguished: geometrical unevenness, which is independent of the loading, and parametric unevenness, which is proportional to the static load of the train. It is important to measure the unevenness spectra under different loading conditions. 
Based on a case history for metro line M1 of ATM in Milan, it is concluded that it is realistic to assume that besides rail unevenness, also slab unevenness, bent rail and variation of rail support stiffness can be perceived. Track engineers should be aware that the structural elements of a track have an impact on perceived unevenness.

Insertion gain functions were defined, describing how perceived unevenness is modified when in-track vibration mitigation measures, such as resilient rail supports, are installed. An important reduction in perceived unevenness may occur when the unevenness source is located beneath the resilient element, whereas an increase is possible otherwise. Unevenness smoothing is a likely explanation for the often observed reduction in low frequency vibration levels after the installation of resilient rail supports. If the dominant unevenness sources are not known, it remains important to measure the unevenness before and after the installation of a vibration mitigation measure in order to correctly asses the performance of the vibration countermeasure.

\section{Acknowledgements}

The first author is a doctoral fellow of the Research Foundation Flanders (FWO). The financial support is gratefully acknowledged. The authors thank Steve Cox from Pandrol for providing information on track construction and measurement data for metro line M1 of ATM in Milan, as well as Olivier Favotte of Pandrol CDM Track for providing information on slab mat stiffness variations.

\section{A. Perturbation analysis}

The perturbation analysis is illustrated for the case of variation of rail support stiffness. Suppose that the rail pad stiffness can be expressed as the sum of a mean stiffness $k_{\mathrm{r} 0}$ and a small variation $\varepsilon w_{k_{\mathrm{r}}}(x) k_{\mathrm{r} 0}$ :

$$
k_{\mathrm{r}}(x)=\left(1+\varepsilon w_{k_{\mathrm{r}}}(x)\right) k_{\mathrm{r} 0},
$$

where $\varepsilon$ is a small constant and $w_{k_{\mathrm{r}}}(x)$ is a dimensionless function that represents the spatial variation of the rail pad stiffness $k_{\mathrm{r}}(x)$ about its mean value $k_{\mathrm{r} 0}$. The equilibrium equations of the track can be written as:

$$
\begin{aligned}
\frac{\mathrm{d}^{4} u_{\mathrm{r} y}}{\mathrm{~d} x^{4}}+\left(1+\varepsilon w_{k_{\mathrm{r}}}(x)\right) \alpha_{\mathrm{rr} 0}\left(u_{\mathrm{r} y}-u_{\mathrm{s} y}\right) & =\frac{P_{\mathrm{s}}}{E I_{\mathrm{r}}} \delta\left(x-x_{\mathrm{P}}\right) \\
\frac{\mathrm{d}^{4} u_{\mathrm{s} y}}{\mathrm{~d} x^{4}}+\alpha_{\mathrm{ss}} u_{\mathrm{s} y}-\left(1+\varepsilon w_{k_{\mathrm{r}}}(x)\right) \alpha_{\mathrm{r} \mathrm{r} 0}\left(u_{\mathrm{r} y}-u_{\mathrm{s} y}\right) & =0 .
\end{aligned}
$$

The products of the function $w_{k_{\mathrm{r}}}(x)$ with the displacements $u_{\mathrm{r} y}(x)$ and $u_{\mathrm{s} y}(x)$ prohibit a simple solution by means of the Fourier transform. Instead, an approximate solution is found using perturbation analysis. 
Let $u_{\mathrm{r} y 0}(x)$ and $u_{\mathrm{s} y 0}(x)$ be the deflected shape of the rail and the slab with a load $P_{\mathrm{s}}$ applied at $x=x_{\mathrm{P}}$ for the case of uniform rail support stiffness $k_{\mathrm{r} 0}(\varepsilon=0)$. The solutions $u_{\mathrm{r} y}(x)$ and $u_{\mathrm{s} y}(x)$ are subsequently expressed as the following power series of $\varepsilon$ :

$$
\begin{aligned}
& u_{\mathrm{r} y}(x)=u_{\mathrm{r} y 0}(x)+\varepsilon u_{\mathrm{r} y 1}(x)+\varepsilon^{2} u_{\mathrm{r} y 2}(x)+\ldots \\
& u_{\mathrm{s} y}(x)=u_{\mathrm{s} y 0}(x)+\varepsilon u_{\mathrm{s} y 1}(x)+\varepsilon^{2} u_{\mathrm{s} y 2}(x)+\ldots
\end{aligned}
$$

These expressions are substituted in the equilibrium equations (A.2) and (A.3) to give:

$$
\begin{aligned}
& \frac{\mathrm{d}^{4}\left(u_{\mathrm{r} y 0}+\varepsilon u_{\mathrm{r} y 1}+\varepsilon^{2} u_{\mathrm{r} y 2}+\ldots\right)}{\mathrm{d} x^{4}}+\left(1+\varepsilon w_{k_{\mathrm{r}}}(x)\right) \alpha_{\mathrm{rr} 0}\left(u_{\mathrm{r} y 0}+\varepsilon u_{\mathrm{r} y 1}+\varepsilon^{2} u_{\mathrm{r} y 2}+\ldots\right) \\
& \quad-\left(1+\varepsilon w_{k_{\mathrm{r}}}(x)\right) \alpha_{\mathrm{rr} 0}\left(u_{\mathrm{s} y 0}+\varepsilon u_{\mathrm{s} y 1}+\varepsilon^{2} u_{\mathrm{s} y 2}+\ldots\right)=\frac{P_{\mathrm{s}}}{E I_{\mathrm{r}}} \delta\left(x-x_{\mathrm{P}}\right), \\
& \frac{\mathrm{d}^{4}\left(u_{\mathrm{s} y 0}+\varepsilon u_{\mathrm{s} y 1}+\varepsilon^{2} u_{\mathrm{s} y 2}+\ldots\right)}{\mathrm{d} x^{4}}+\alpha_{\mathrm{ss}}\left(u_{\mathrm{s} y 0}+\varepsilon u_{\mathrm{s} y 1}+\varepsilon^{2} u_{\mathrm{s} y 2}+\ldots\right) \\
& \quad+\left(1+\varepsilon w_{k_{\mathrm{r}}}(x)\right) \alpha_{\mathrm{r} \mathrm{r} 0}\left(u_{\mathrm{s} y 0}+\varepsilon u_{\mathrm{s} y 1}+\varepsilon^{2} u_{\mathrm{s} y 2}+\ldots\right) \\
& \quad-\left(1+\varepsilon w_{k_{\mathrm{r}}}(x)\right) \alpha_{\mathrm{r} \mathrm{r} 0}\left(u_{\mathrm{r} y 0}+\varepsilon u_{\mathrm{r} y 1}+\varepsilon^{2} u_{\mathrm{r} y 2}+\ldots\right)=0 .
\end{aligned}
$$

The sum of all zero-th order terms in $\varepsilon$ in these equations equals zero, corresponding to the equilibrium equations of the slab track without unevenness. In a first order perturbation analysis, the first order terms in $\varepsilon$ are collected, resulting in the following set of differential equations for $u_{\mathrm{r} y 1}$ and $u_{\mathrm{s} y 1}$ :

$$
\begin{aligned}
\frac{\mathrm{d}^{4} u_{\mathrm{r} y 1}}{\mathrm{~d} x^{4}}+\alpha_{\mathrm{r} r 0}\left(u_{\mathrm{r} y 1}-u_{\mathrm{s} y 1}\right) & =-w_{k_{\mathrm{r}}}(x) \alpha_{\mathrm{rr} 0}\left(u_{\mathrm{r} y 0}-u_{\mathrm{s} y 0}\right), \\
\frac{\mathrm{d}^{4} u_{\mathrm{s} y 1}}{\mathrm{~d} x^{4}}+\alpha_{\mathrm{ss}} u_{\mathrm{s} y 1}+\alpha_{\mathrm{r} 0}\left(u_{\mathrm{s} y 1}-u_{\mathrm{r} y 1}\right) & =-w_{k_{\mathrm{r}}}(x) \alpha_{\mathrm{r} \mathrm{s} 0}\left(u_{\mathrm{s} y 0}-u_{\mathrm{r} y 0}\right) .
\end{aligned}
$$

The right hand sides of these equations contain products of the function $w_{k_{\mathrm{r}}}(x)$ and the displacements $u_{\mathrm{r} y 0}$ and $u_{\mathrm{s} y 0}$. The Fourier transform of these equations is equal to:

$$
\left[\begin{array}{cc}
k_{x}^{4}+\alpha_{\mathrm{rr} 0} & -\alpha_{\mathrm{rr} 0} \\
-\alpha_{\mathrm{r} 0} & k_{x}^{4}+\alpha_{\mathrm{ss}}+\alpha_{\mathrm{r} 0}
\end{array}\right]\left\{\begin{array}{c}
\tilde{u}_{\mathrm{r} y 1}\left(k_{x}\right) \\
\tilde{u}_{\mathrm{s} y 1}\left(k_{x}\right)
\end{array}\right\}=\left\{\begin{array}{c}
-\frac{\alpha_{\mathrm{rr} 0}}{2 \pi} \tilde{w}_{k_{\mathrm{r}}}\left(k_{x}\right) *\left(\tilde{u}_{\mathrm{r} y 0}\left(k_{x}\right)-\tilde{u}_{\mathrm{s} y 0}\left(k_{x}\right)\right) \\
-\frac{\alpha_{\mathrm{rs} 0}}{2 \pi} \tilde{w}_{k_{\mathrm{r}}}\left(k_{x}\right) *\left(\tilde{u}_{\mathrm{s} y 0}\left(k_{x}\right)-\tilde{u}_{\mathrm{r} y 0}\left(k_{x}\right)\right)
\end{array}\right\},
$$

where the convolution integrals in the right hand side are defined as:

$$
\tilde{w}_{k_{\mathrm{r}}}\left(k_{x}\right) * \tilde{u}_{\mathrm{r} y 0}\left(k_{x}\right)=\int_{-\infty}^{\infty} \tilde{w}_{k_{\mathrm{r}}}(u) \tilde{u}_{\mathrm{r} y 0}\left(k_{x}-u\right) \mathrm{d} u
$$

and $\tilde{u}_{\mathrm{r} y 0}\left(k_{x}\right)$ and $\tilde{u}_{\mathrm{s} y 0}\left(k_{x}\right)$ follow from equations (9) and (10):

$$
\begin{aligned}
& \tilde{u}_{\mathrm{r} y 0}\left(k_{x}\right)=\frac{P_{\mathrm{s}}}{E I_{\mathrm{r}}} \frac{k_{x}^{4}+\alpha_{\mathrm{rs} 0}+\alpha_{\mathrm{ss}}}{D_{0}\left(k_{x}\right)} \mathrm{e}^{+\mathrm{j} k_{x} x_{\mathrm{P}}}, \\
& \tilde{u}_{\mathrm{s} y 0}\left(k_{x}\right)=\frac{P_{\mathrm{s}}}{E I_{\mathrm{r}}} \frac{\alpha_{\mathrm{r} 0}}{D_{0}\left(k_{x}\right)} \mathrm{e}^{+\mathrm{j} k_{x} x_{\mathrm{P}}},
\end{aligned}
$$


where the denominator denominator $D_{0}\left(k_{x}\right)=k_{x}^{8}+k_{x}^{4}\left(\alpha_{\mathrm{rs} 0}+\alpha_{\mathrm{rr} 0}+\alpha_{\mathrm{ss}}\right)+\alpha_{\mathrm{rr} 0} \alpha_{\mathrm{ss}}$. The system of equations (A.10) is solved for $\tilde{u}_{\mathrm{r} y 1}\left(k_{x}\right)$ :

$$
\tilde{u}_{\mathrm{r} y 1}\left(k_{x}\right)=-\frac{\alpha_{\mathrm{rr} 0}}{2 \pi} \frac{\left(k_{x}^{4}+\alpha_{\mathrm{ss}}\right)}{D_{0}\left(k_{x}\right)} \tilde{w}_{k_{\mathrm{r}}}\left(k_{x}\right) *\left(\tilde{u}_{\mathrm{r} y 0}\left(k_{x}\right)-\tilde{u}_{\mathrm{s} y 0}\left(k_{x}\right)\right) .
$$

The vertical rail displacement at $x=x_{\mathrm{P}}$ below the applied force is found by evaluating the inverse wavenumber transform for $x=x_{\mathrm{P}}$ :

$$
u_{\mathrm{r} y 1}\left(x_{\mathrm{P}}\right)=-\frac{\alpha_{\mathrm{rr} 0}}{(2 \pi)^{2}} \int_{-\infty}^{\infty} \frac{k_{x}^{4}+\alpha_{\mathrm{ss}}}{D_{0}\left(k_{x}\right)} \int_{-\infty}^{\infty} \tilde{w}_{k_{\mathrm{r}}}(u)\left(\tilde{u}_{\mathrm{r} y 0}\left(k_{x}-u\right)-\tilde{u}_{\mathrm{s} y 0}\left(k_{x}-u\right)\right) \mathrm{d} u \mathrm{e}^{-\mathrm{j} k_{x} x_{\mathrm{P}}} \mathrm{d} k_{x} .
$$

Substituting for $\tilde{u}_{\mathrm{r} y 0}\left(k_{x}\right)$ and $\tilde{u}_{\mathrm{s} y 0}\left(k_{x}\right)$ results in:

$$
u_{\mathrm{r} y 1}\left(x_{\mathrm{P}}\right)=-\frac{\alpha_{\mathrm{rr} 0}}{(2 \pi)^{2}} \frac{P_{\mathrm{S}}}{E I_{\mathrm{r}}} \int_{-\infty}^{\infty} \frac{k_{x}^{4}+\alpha_{\mathrm{SS}}}{D_{0}\left(k_{x}\right)} \int_{-\infty}^{\infty} \tilde{w}_{k_{\mathrm{r}}}(u) \frac{\left(k_{x}-u\right)^{4}+\alpha_{\mathrm{SS}}}{D_{0}\left(k_{x}-u\right)} \mathrm{e}^{+\mathrm{j}\left(k_{x}-u\right) x_{\mathrm{P}}} \mathrm{d} u \mathrm{e}^{-\mathrm{j} k_{x} x_{\mathrm{P}}} \mathrm{d} k_{x} .
$$

Transforming the coordinate $x_{\mathrm{P}}$ to the wavenumber $k_{x_{\mathrm{P}}}$ results in:

$$
\begin{aligned}
\tilde{u}_{\mathrm{r} y 1}\left(k_{x_{\mathrm{P}}}\right)= & -\frac{\alpha_{\mathrm{rr} 0}}{(2 \pi)^{2}} \frac{P_{\mathrm{s}}}{E I_{\mathrm{r}}} \int_{-\infty}^{\infty} \int_{-\infty}^{\infty} \frac{k_{x}^{4}+\alpha_{\mathrm{ss}}}{D_{0}\left(k_{x}\right)} \int_{-\infty}^{\infty} \tilde{w}_{k_{\mathrm{r}}}(u) \frac{\left(k_{x}-u\right)^{4}+\alpha_{\mathrm{ss}}}{D_{0}\left(k_{x}-u\right)} \mathrm{e}^{+\mathrm{j}\left(k_{x}-u\right) x_{\mathrm{P}}} \mathrm{d} u \mathrm{e}^{-\mathrm{j} k_{x} x_{\mathrm{P}}} \mathrm{d} k_{x} \\
& \mathrm{e}^{+\mathrm{j} k_{x_{\mathrm{P}}} x_{\mathrm{P}}} \mathrm{d} x_{\mathrm{P}} .
\end{aligned}
$$

Rearranging the order of integration results in:

$$
\tilde{u}_{\mathrm{r} y 1}\left(k_{x_{\mathrm{P}}}\right)=-\frac{\alpha_{\mathrm{rr} 0}}{(2 \pi)^{2}} \frac{P_{\mathrm{S}}}{E I_{\mathrm{r}}} \int_{-\infty}^{\infty} \int_{-\infty}^{\infty} \tilde{w}_{k_{\mathrm{r}}}(u) \frac{k_{x}^{4}+\alpha_{\mathrm{sS}}}{D_{0}\left(k_{x}\right)} \frac{\left(k_{x}-u\right)^{4}+\alpha_{\mathrm{SS}}}{D_{0}\left(k_{x}-u\right)}\left\{\int_{-\infty}^{\infty} \mathrm{e}^{-j\left(u-k_{x_{\mathrm{P}}}\right) x_{\mathrm{P}}} \mathrm{d} x_{\mathrm{P}}\right\} \mathrm{d} u \mathrm{~d} k_{x} .
$$

The bracketed term is equal to $2 \pi \delta\left(u-k_{x_{\mathrm{P}}}\right)$ so that:

$$
\tilde{u}_{\mathrm{r} y 1}\left(k_{x_{\mathrm{P}}}\right)=-\tilde{w}_{k_{\mathrm{r}}}\left(k_{x_{\mathrm{P}}}\right) \frac{\alpha_{\mathrm{rr} 0}}{2 \pi} \frac{P_{\mathrm{s}}}{E I_{\mathrm{r}}} \int_{-\infty}^{\infty} \frac{k_{x}^{4}+\alpha_{\mathrm{SS}}}{D_{0}\left(k_{x}\right)} \frac{\left(k_{x}-k_{x_{\mathrm{P}}}\right)^{4}+\alpha_{\mathrm{sS}}}{D_{0}\left(k_{x}-k_{x_{\mathrm{P}}}\right)} \mathrm{d} k_{x}
$$

The transfer function $\tilde{T}_{3 \mathrm{a}}\left(k_{x_{\mathrm{P}}}\right)$ between the relative variation $\varepsilon \tilde{w}_{k_{\mathrm{r}}}\left(k_{x_{\mathrm{P}}}\right)$ of the rail support stiffness and the perceived unevenness $\tilde{u}_{3 \mathrm{a}}\left(k_{x_{\mathrm{P}}}\right)=-\varepsilon \tilde{u}_{\mathrm{r} y 1}\left(k_{x_{\mathrm{P}}}\right)$ (minus sign as the static axle load $P_{\mathrm{s}}$ acts downwards) is therefore equal to:

$$
\tilde{T}_{3 \mathrm{a}}\left(k_{x_{\mathrm{P}}}\right)=\frac{\alpha_{\mathrm{rr} 0}}{2 \pi} \frac{P_{\mathrm{s}}}{E I_{\mathrm{r}}} \int_{-\infty}^{\infty} \frac{k_{x}^{4}+\alpha_{\mathrm{SS}}}{D_{0}\left(k_{x}\right)} \frac{\left(k_{x}-k_{x_{\mathrm{P}}}\right)^{4}+\alpha_{\mathrm{sS}}}{D_{0}\left(k_{x}-k_{x_{\mathrm{P}}}\right)} \mathrm{d} k_{x}
$$

The inverse wavenumber integral can be evaluated analytically using contour integration.

\section{B. Rail receptance of the slab track}

The system of equilibrium equations for a slab track with constant bending stiffness $E I_{\mathrm{r}}$ and $E I_{\mathrm{s}}$ of the rail and the slab, subjected to a harmonic load with amplitude $\hat{P}_{\mathrm{s}}$ and excitation frequency $\omega$ at position 
$x=0$, can be written in the frequency domain as:

$$
\begin{aligned}
\frac{\mathrm{d}^{4} \hat{u}_{\mathrm{r} y}}{\mathrm{~d} x^{4}}-\omega^{2} \beta_{\mathrm{rr}} \hat{u}_{\mathrm{r} y}+\alpha_{\mathrm{rr}}\left(\hat{u}_{\mathrm{r} y}-\hat{u}_{\mathrm{s} y}\right) & =\frac{\hat{P}_{\mathrm{s}}}{E I_{\mathrm{r}}} \delta(x), \\
\frac{\mathrm{d}^{4} \hat{u}_{\mathrm{s} y}}{\mathrm{~d} x^{4}}-\omega^{2} \beta_{\mathrm{ss}} \hat{u}_{\mathrm{s} y}+\alpha_{\mathrm{ss}} \hat{u}_{\mathrm{s} y}+\alpha_{\mathrm{rs}}\left(\hat{u}_{\mathrm{s} y}-\hat{u}_{\mathrm{r} y}\right) & =0
\end{aligned}
$$

where $\beta_{\mathrm{rr}}=m_{\mathrm{r}} /\left(E I_{\mathrm{r}}\right)$ and $\beta_{\mathrm{ss}}=m_{\mathrm{s}} /\left(E I_{\mathrm{s}}\right)$. These equations are transformed to the frequency-wavenumber domain:

$$
\left[\begin{array}{cc}
k_{x}^{4}-\beta_{\mathrm{rr}} \omega^{2}+\alpha_{\mathrm{rr}} & -\alpha_{\mathrm{rr}} \\
-\alpha_{\mathrm{rs}} & k_{x}^{4}-\beta_{\mathrm{ss}} \omega^{2}+\alpha_{\mathrm{ss}}+\alpha_{\mathrm{rs}}
\end{array}\right]\left\{\begin{array}{c}
\tilde{u}_{\mathrm{r} y}\left(k_{x}, \omega\right) \\
\tilde{u}_{\mathrm{s} y}\left(k_{x}, \omega\right)
\end{array}\right\}=\left\{\begin{array}{c}
\hat{P}_{\mathrm{s}} \\
\hline E I_{\mathrm{r}} \\
0
\end{array}\right\} .
$$

which can be solved to obtain the rail and slab displacement in the frequency-wavenumber domain. The rail displacement is equal to:

$$
\tilde{u}_{\mathrm{r} y}\left(k_{x}, \omega\right)=\frac{\hat{P}_{\mathrm{s}}}{E I_{\mathrm{r}}} \frac{k_{x}^{4}-\beta_{\mathrm{ss}} \omega^{2}+\alpha_{\mathrm{ss}}+\alpha_{\mathrm{rs}}}{D\left(k_{x}, \omega\right)}
$$

with $D\left(k_{x}, \omega\right)$ the determinant of the coefficient matrix at the left hand side of equation (B.3). The inverse wavenumber transformation to the frequency domain results into:

$$
\hat{u}_{\mathrm{r} y}(x, \omega)=\frac{1}{2 \pi} \frac{\hat{P}_{\mathrm{s}}}{E I_{\mathrm{r}}} \int_{-\infty}^{+\infty} \frac{k_{x}^{4}-\beta_{\mathrm{ss}} \omega^{2}+\alpha_{\mathrm{ss}}+\alpha_{\mathrm{rs}}}{D\left(k_{x}, \omega\right)} e^{-\mathrm{j} k_{x} x} \mathrm{~d} k_{x} .
$$

The rail displacement $\hat{u}_{\mathrm{r} y}(0, \omega)$ under the load is equal to:

$$
\hat{u}_{\mathrm{r} y}(0, \omega)=\frac{1}{2 \pi} \frac{\hat{P}_{\mathrm{s}}}{E I_{\mathrm{r}}} \int_{-\infty}^{+\infty} \frac{k_{x}^{4}-\beta_{\mathrm{ss}} \omega^{2}+\alpha_{\mathrm{ss}}+\alpha_{\mathrm{rs}}}{D\left(k_{x}, \omega\right)} \mathrm{d} k_{x}=\hat{H}_{\mathrm{yr}}(\omega) \hat{P}_{\mathrm{s}},
$$

where $\hat{H}_{\mathrm{yr}}(\omega)$ is the rail receptance of the slab track:

$$
\hat{H}_{\mathrm{yr}}(\omega)=\frac{1}{2 \pi} \frac{1}{E I_{\mathrm{r}}} \int_{-\infty}^{+\infty} \frac{k_{x}^{4}-\beta_{\mathrm{ss}} \omega^{2}+\alpha_{\mathrm{ss}}+\alpha_{\mathrm{rs}}}{D\left(k_{x}, \omega\right)} \mathrm{d} k_{x}
$$

The integral can be evaluated analytically using contour integration.

\section{References}

[1] S. Cox, D. Herron, A review of measurement data on the performance of a resilient track form as a mitigation measure for ground-borne noise, in: J. Nielsen, D. Anderson, P.-E. Gautier, M. Iida, J. Nelson, D. Thompson, T. Tielkes, D. Towers, P. de Vos (Eds.), Noise and Vibration Mitigation for Rail Transportation Systems, Vol. 126 of Notes on Numerical Fluid Mechanics and Multidisciplinary Design, Springer Berlin/Heidelberg, 2015, pp. 611-618.

[2] X. Sheng, C. Jones, D. Thompson, A comparison of a theoretical model for quasi-statically and dynamically induced environmental vibration from trains with measurements, Journal of Sound and Vibration 267 (3) (2003) 621-635.

[3] L. Auersch, Theoretical and experimental excitation force spectra for railway-induced ground vibration: vehicle-track-soil interaction, irregularities and soil measurements, Vehicle Systems Dynamics 48 (2) (2010) $235-261$. 
[4] E. Berggren, M. Li, J. Spännar, A new approach to the analysis and presentation of vertical track geometry quality and rail roughness, Wear 265 (9) (2008) 1488-1496.

[5] E. Verheijen, A survey on roughness measurements, Journal of Sound and Vibration 293 (3) (2006) $784-794$.

[6] T. Wu, D. Thompson, On the parametric excitation of the wheel/track system, Journal of Sound and Vibration 278 (4-5) (2004) 725-747.

[7] B. Nélain, N. Vincent, G. Lombaert, G. Degrande, Control of railway induced ground vibrations: Influence of excitation mechanisms on the efficiency of resilient track layers, in: J. Nielsen, D. Anderson, P. de Vos, P.-E. Gautier, M. Iida, J. Nelson, T. Tielkes, D. Thompson, D. Towers (Eds.), Proceedings of the 11th International Workshop on Railway Noise IWRN11, Uddevalla, Sweden, 2013, pp. 703-710.

[8] B. Nélain, N. Vincent, The effect of parametric excitation on ground borne vibration in railway applications, in: A. Cunha, E. Caetano, P. Ribeiro, G. Müller (Eds.), Proceedings of 9th International Conference on Structural Dynamics (EURODYN 2014), Porto, Portugal, 2014, pp. 847-853.

[9] H. Hunt, Types of rail roughness and the selection of vibration isolation measures, in: B. Schulte-Werning, D. Thompson, P.-E. Gautier, C. Hanson, B. Hemsworth, J. Nelson, T. Maeda, P. de Vos (Eds.), Noise and Vibration Mitigation for Rail Transportation Systems, Vol. 99 of Notes on Numerical Fluid Mechanics and Multidisciplinary Design, Springer Berlin/Heidelberg, 2008, pp. 341-347.

[10] E. Winkler, Die Lehre von der Elastizität und Festigkeit, Dominicus Prague, Czechoslovakia, 1867.

[11] M. Hetényi, Beams on Elastic Foundation: Theory with Applications in the Fields of Civil and Mechanical Engineering, Vol. 16 of University of Michigan studies: Scientific series, University of Michigan Press, 1946.

[12] L. Auersch, Excitation of ground vibration due to the passage of trains over a track with trackbed irregularities and a varying support stiffness, Vehicle Systems Dynamics 53 (1) (2015) 1-29.

[13] R. Verachtert, The effect of track unevenness on railway-induced ground vibrations, Master's thesis, Department of Civil Engineering, KU Leuven, Erasmus, Cambridge University, United Kingdom (2013).

[14] N.N., Installation and testing of Pandrol Vanguard system on ATM line M1, Tech. Rep. 85671-12, Pandrol Limited, Surrey, UK (2003).

[15] P. Mathews, Vibrations of a beam on elastic foundation, ZAMM-Journal of Applied Mathematics and Mechanics/Zeitschrift für Angewandte Mathematik und Mechanik 38 (3-4) (1958) 105-115.

[16] P. Mathews, Vibrations of a beam on elastic foundation II, ZAMM-Journal of Applied Mathematics and Mechanics/Zeitschrift für Angewandte Mathematik und Mechanik 39 (1-2) (1959) 13-19.

[17] M. Shamalta, A. Metrikine, Analytical study of the dynamic response of an embedded railway track to a moving load, Archive of Applied Mechanics 73 (1-2) (2003) 131-146.

[18] J. Forrest, H. Hunt, A three-dimensional tunnel model for calculation of train-induced ground vibration, Journal of Sound and Vibration 294 (4) (2006) 678-705.

[19] J. Forrest, H. Hunt, Ground vibration generated by trains in underground tunnels, Journal of Sound and Vibration 294 (4) (2006) 706-736.

[20] M. Hussein, H. Hunt, Modelling of floating-slab tracks with continuous slabs under oscillating moving loads, Journal of Sound and Vibration 297 (1) (2006) 37-54.

[21] C.-M. Kuo, C.-H. Huang, Y.-Y. Chen, Vibration characteristics of floating slab track, Journal of Sound and Vibration 317 (3) (2008) 1017-1034.

[22] D. Thompson, Railway noise and vibration: mechanisms, modelling, and means of control, Elsevier, Oxford, 2009.

[23] M. Hussein, H. Hunt, A numerical model for calculating vibration from a railway tunnel embedded in a full-space, Journal of Sound and Vibration 305 (3) (2007) 401-431.

[24] X. Sheng, C. Jones, D. Thompson, A theoretical model for ground vibration from trains generated by vertical track irregularities, Journal of Sound and Vibration 272 (3) (2004) 937-965.

[25] A. Wunsch, Complex Variables with Applications, Addison-Wesley Series in Mathematics, Addison-Wesley, 1983.

[26] J. Egana, J. Vinolas, M. Seco, Investigation of the influence of rail pad stiffness on rail corrugation on a transit system, Wear 261 (2) (2006) 216-224.

[27] M. Hussein, Vibration from underground railways, Ph.D. thesis, Department of Engineering, University of Cambridge (2004).

[28] P. Costa, R. Calçada, A. Cardoso, Influence of train dynamic modelling strategy on the prediction of track-ground vibrations induced by railway traffic, Proceedings of the Institution of Mechanical Engineers, Part F: Journal of Rail and Rapid Transit 226 (4) (2012) 434-450.

[29] H. Hertz, Über die Berührung fester elastischer Körper, Journal für die reine und angewandte Mathematik 92 (1881) $156-171$.

[30] K. Johnson, Contact Mechanics, Cambridge University Press, 1987.

[31] T. Wu, D. Thompson, Theoretical investigation of wheel/rail non-linear interaction due to roughness excitation, Vehicle Systems Dynamics 34 (4) (2000) 261-282.

[32] J. Forrest, Modelling of ground vibration from underground railways, Ph.D. thesis, Department of Engineering, University of Cambridge (1999).

[33] BSI, BS EN 13674-1:2011: Railway applications - Track - Rail - Part 1: Vignole railway rails 46 kg/m and above, British Standards Institution (February 2011).

[34] A. Bracciali, F. Piccioli, D. Benedetto, Rail straightness control in service, in: B. Topping, Y. Tsompanakis (Eds.), Proceedings of the Thirteenth International Conference on Civil, Structural and Environmental, Engineering Computing, Crete, Greece, 2011, pp. 1-12.

[35] N.N., Evaluation of PANDROL Brand Rail Pads type 6530, Tech. Rep. 36486-71, Pandrol Limited, Surrey, UK (2008). 
[36] D. Thompson, W. van Vliet, Measurements of the High Frequency Dynamic Properties of Swedish Rail Pads, Tech. Rep. TPD-HAG-RPT-960066, TNO Institute of Applied Physics, Delft, The Netherlands (1996).

[37] O. Favotte, Pandrol CDM Track, Personal communication, June 2014 (2014).

[38] D. Newland, An Introduction to Random Vibrations, Spectral \& Wavelet Analysis, 3rd Edition, Longman Scientific \& Technical, Harlow, Essex, England, 1993. 